\title{
El tema de Dios y del hombre en la fenomenología de M. Scheler*
}

\author{
CAPITULO QUINTO
}

\author{
EIDOLOGIAA DE LOS ACTOS
}

Antes de adentrarnos en la exposición fenomenológica del acto religioso como correlato esencial del objeto religioso, nos proponemos trazar las líneas generales de la eidología de los actos en general, que con la de los objetos y las correlaciones esenciales entre ambos configuran la fenomenología tridimensional de M. Scheler como estructura unitaria indivisible.

En la eidología de los actos nos vemos precisados a anticipar necesariamente conceptos que encuentran su sentido adecuado dentro de la concepción scheleriana de upersona». Remitimos, pues, a nuestra Tercera Parte a fin de obtener una visión coherente y comprensiva de la totalidad.

\section{Estructura formal de los actos}

El principio fenomenológico fundamental scheleriano señala la existencia de una correlación esencial entre el objeto y el acto.

Este axioma originario implica una dualidad significativa:

a) Perfecta disyunción entre la esencia del objeto y la del acto.

Ningún ser puede pertenecer simultáneamente a la esfera de los actos y a la de los objetos; ningún acto puede ser objetivable igual que ningún objeto puede manifestar un carácter eminentemente «actual».

b) Si las cualidades y direcciones diferenciales de los actos tienen una estricta correspondencia con las regiones esenciales de los objetos, determinados objetos pueden «aparecer» (erscheinen) sólo en actos cualitativamente

* Cfr. Estudio Agustiniano, 13(1978) 456-522 y 14(1979) 71-122. 
específicos, igual que determinados actos sólo pueden apuntar hacia objetos con estruictura esencial especifica.

La conexión esencial entre acto y objeto tiene el carácter de una relación condicionante reciproca, en virtud de la que todo objeto posible puede ser aprehendido en un acto, del mismo modo que todo acto tiende intencionalmente a un objeto. De aquí emerge como característica esencial de los actos la «intencionalidad» e.d., los actos señalan más allá del acto y del contenido actual del acto, en el acto se significa un objeto «pudiendo sólo aparecer el objeto en su realización» ${ }^{267}$.

Intencionalidad no significa necesariamente que todos los actos han de apuntar directamente a un objeto, que todos los actos han de aprehender siempre algo objetual: el acto de la ureflexio» no apunta a algo objetual.

Todo acto, en cuanto inobjetivable, consiste en su «realización» (Vollzug). Pero de alguna forma tiene que «darse» el ser inobjetivable del acto, de alguna forma ha de aparecer a si mismo. La dimensión óntica del acto le obliga a que esto sólo sea posible en virtud de una participación óntica en la «actualidad» pura.

Ahora bien, la «co-realización» de actos tiende de manera indirecta hacia el objeto, ya que por medio del acto realizado apunta al objeto del mismo, pero aprehende además el contenido del acto en cuanto acto y el sujeto del acto.

Existe, como veremos, en $M$. Scheler una clase de actos (la reflexión) que se dirige exclusivamente a las cualidades mismas de los actos en cuanto actos.

Si se designa, pues, como «intencionalidad» este apuntar-hacia del acto co-realizador y de la reflexión, puede afirmarse que tiene un sentido estricto y otro amplio:

a) el apuntar del acto al objeto,

b) el señalar-más-allá de sí mismo.

La intencionalidad en sentido amplio es propia de todos los actos en general: todo acto señala más allá del acto y del contenido del acto.

Propio del acto intencional en sentido estricto es la conciencia de trascendencia perteneciente a la estructura de la intencionalidad objetual del acto. En la conciencia-de-algo- en cuanto objeto se da un saber sobre la autonomía del objeto respecto a la realización del acto en el que se manifiesta.

El sentido amplio de la intencionalidad no contradice al principio fenomenológico fundamental ya que en éste se establece una correspondencia esencial entre objeto y acto dentro del orden esencial mientras que aquélla indica un mero apuntar más allá de sí.

Con el término "conciencia-de-algo» presenta M. Scheler una nueva determinación en la estructura formal de los actos.

267. Eth. 264. 
Es propio de las «intenciones» cualitativamente diferentes del espíritu el carácter «actual».

Ahora bien, el ser espiritual abarca tanto la vertiente teórica como la emocional.

A todos estos actos, cualitativamente diferentes, les es común el ser «noesis». De aquí que se encuentre en toda intención del acto un saber inmediato y prelógico de sus objetos. Esta «conciencia-de-algo» presente en todos los actos no es una mera «representación» de los objetos ${ }^{268}$ en cuanto «objetivación-actual que fundamenta todos los demás actos intencionales» ${ }^{269}$, es más bien el momento aprehensor y noético inherente a toda dirección intencional de los actos.

Los actos tienen una determinación ulterior en su relación esencial con el «contenido-de-sentido» intemporal, que constituye un nuevo momento estructural de la intencionalidad.

Los actos están «llenos de sentido» y poseen una correlación significativa entre sí.

Las estructuras significativas son elementos integrantes de la comprensión de los actos. Sin embargo, al verificarse la aprehensión «actual» de las estructuras de sentido en la co-realización o post-ejecución de los actos, tal comprensión no tiene nada que ver con el mero «entender» conceptual-causal de la psicología "comprensiva».

Junto a su principio fenomenológico fundamental presenta M. Scheler un sentido-objetivo-en-sí, que trasciende a la realización de los actos.

Ahora bien, ¿constituye el sentido la objetualidad del objeto? ¿Se manifiesta el sentido en, con o como objeto solamente? ¿Están llenos los actos de sentido únicamente en cuanto tienden a los objetos?

Ante estas preguntas que hemos de formularnos dentro de la eidología scheleriana de los actos, parece que el principio fenomenológico fundamental se hunde en un mar de confusiones y vaguedades.

Los contenidos significativos y sus conexiones esenciales parecen constituir en M. Scheler como un puente entre el objeto y el acto.

Sin embargo, nos parece que los actos en su realización no son meros receptores de estructuras de sentido consistentes en sí y con plena autonomía frente a la realización de los actos.

En la realización fáctica de actos se dan conexiones significativas y síntesis de sentido absolutamente específicas. Tales síntesis han de ser inobjetivables y nunca pueden interpretarse como consistentes en sí ya que sólo son posibles por la espontaneidad del sujeto de actos.

Aquí converge, precisamente, el sentido de los actos en la forma de unidad de los mismos: la persona espiritual totalmente inespacial e intemporal.

268. Nachl. 384.

269. Eth. 391. 

Por otra parte tienen los actos, entre sí, un orden originario dentro del tiempo que se refleja en el momento temporal de los contenidos objetivos de los actos ${ }^{272}$.

En la realización del acto existe una actitud consciencial crítica, consistente en que el sujeto de actos, la persona espiritual, no se agota en la realización de los mismos, sino que revierte sobre la conciencia de los actos:

«Esta reflexión no es ninguna «objetivación», ninguna clase de «percepción...» es una mera vibración incualificada de la "conciencia-de» en el actorealizador» ${ }^{273}$.

La conciencia reflexiva es concomitante pero no objetivante.

Si M. Scheler exige intencionalidad a esta «reflexión», sólo puede entenderse en el sentido de que señala más allá de sí, en cuanto apunta a algo que no es ella: al acto mismo.

Sólo aquellas esencias de actos que pertenecen a la unidad existencial de la persona pueden darse a una reflexión, no lo perteneciente a la pura posibilidad del ser del acto.

Lo específico de la reflexión se encuentra precisamente en que se dirige intencionalmente $y$ de manera exclusiva a las mismas esencias de actos. Con ello se encuentra dentro de las fronteras de la intuición fenomenológica.

La reflexión revierte sobre el puro qué de los actos no sobre su ser-derealización.

«Aquello a lo que dirijo mi mirada no es nunca el acto mismo, sino algo que pertenece a su contenido» ${ }^{274}$.

Esto indica que la actualidad pura es trasconsciente y por tanto no comprensible fenomenológicamente: únicamente por la participación en su mismo ser, por la «realización» de los actos puede lograrse un saber-nointencional sobre su forma de ser específica, completando asi la teoría scheleriana del saber como "participación óntica» (Seinsteilnahme) su concepción fenomenológica.

272. Eth. 462, nota.

273. U. d. W. 234.

274. U. d. W. 234. 


\section{CAPITULO SEXTO}

\section{EIDOLOGÍA DEL ACTO RELIGIOSO}

\section{EL ACTO RELIGIOSO COMO ÚNICO ACCESO POSIBLE A LA ESFERA DEL ABSOLUTO.}

Vamos a seguir en el presente capítulo el pensamiento scheleriarıo tal y como es expuesto en De lo Eterno en el hombre. Sin embargo, es de suma importancia destacar la transición continua operada por $M$. Scheler que pasa - consciente o inconscientemente - de una perspectiva fenomenológica a una experiencia-religiosa, que desde aquélla ha de parecer absolutamente dogmática e intolerable en un fenomenólogo.

En el siguiente capítulo intentaremos presentar algunas precisiones al respecto a fin de obtener una comprensión adecuada de la significación $y$ límites de la eidología del acto religioso en $\mathrm{M}$. Scheler.

Si existe, como hemos podido constatar en el capítulo anterior, una correlación esencial entre el objeto y el acto en el que se manifiesta aquél ${ }^{275}$, de modo que a todo "fenómeno originario» hay que asignarle una forma específica de experiencia ${ }^{276}$. Si todo ser incluye en sí -al menos como posibilidad - la forma específica de conocimiento del mismo, siendo contradictoria "la idea de un ser totalmente incognoscible» ${ }^{27}$, es una consecuencia fenomenológica que la "esfera» del Absoluto, que como toda esfera del ser no puede inferirse de otra distinta dada su irreductibilidad, tiene una correlación esencial con el acto en el que se manifiesta: el acto religioso. Acto y objeto constituyen una estructura unitaria indestructible:

"Los actos religiosos y su esfera objetiva de ser y de valor.manifiestan una totalidad cerrada en sí misma, tan originaria como los actos de la esencia de la percepción externa y del mundo exterior» ${ }^{278}$.

Dado el carácter originario del acto religioso, que por lo demás no pro-

275. Eth. 264 .

276. Eth. 261.

277. Ew. M. 181

278. Ew. M. 169. 
viene solamente de la correlación esencial existente entre la esfera objetiva del ser y valor religiosos y aquél, sino también de que «la relación del hombre con lo divino es constitutivo esencial del hombre mismo» ${ }^{279}$, prescinde M. Scheler de toda pregunta genética, psicológica y crítica al no tener ningún sentido dado el carácter apriorístico de la esfera del absoluto y de su acto correspondiente. Tales preguntas, como hemios visto en el capítulo anterior, podrían formularse en función del «momento temporal» en el que aparecen los contenidos objetivos de los actos ${ }^{280}$, pero desde la perspectiva de la actitud fenomenológica que prescinde de todo coeficiente de la realidad, son excluidas expresamente por M. Scheler.

De la correlación esencial entre el objeto y el acto emerge el hecho de que la particularidad del acto religioso esté condicionada precisamente por la región esencial del objeto religioso, igual que el hecho de que el acto religioso sea el único acceso posible a la esfera del Absoluto.

\section{ESTRUCTURA INTERNA DEL ACTO RELIGIOSO}

Al ser el acto religioso correlato noético esencial de lo Divino, aparece claro que éste se proyecte en aquél ${ }^{281}$.

El acto religioso es anterior al racional y fundamento del mismo. La experiencia de lo Divino testifica, de una manera inmediata, «que el alma tiene una determinación que trasciende a la vida, que participa de un reino ónticoaxiológico suprasensible, cuyos contenidos no pueden dimanar de la experiencia de cosas finitas» ${ }^{282}$, siendo este carácter intencional el que hace que no se hunda el acto religioso en sí mismo, sino que se fundamente en lo objetivo divino que es trascendente a él y causa del mismo.

Esta característica esencial del acto religioso excluye toda postura subjetivista. Si fuera solamente "un fenómeno que se realiza en la vertiente subjetiva», si no le correspondiera una "materia originaria de acto» ${ }^{283}$, sería totalmente inmanente. Pero por su «intencionalidad» dirigida a lo Divino «abre al hombre una mirada sobre el mundo del ser objetivo, que permanecería por otra parte, totalmente oculto's ${ }^{284}$.

Al superar toda postura inmanentista, tiende un puente que une al hombre inmediatamente con lo divino: "Los actos religiosos no pueden ser meros deseos, indigencias, añoranzas, ni algo similar, ya que tienden intencionalmente a un reino de objetos esencialmente distintos» ${ }^{285}$. El acto reli-

279. Ew. M. 257-258.

280. Eth. 462, nota.

281. Ew. M. 255.

282. Ew. M. 257-258.

283. Ew. M. 276.

284. Ew. M. 277.

285. Ew. M. 242. 
gioso no «imagina» o "construye» un objeto con ayuda de la espontaneidad de la razón, sino que le viene dado, recibe la verdad que busca, precisamente de aquél a quien tiende.

A estas alturas está claro que M. Scheler rechaza toda concepción subjetivista de lo Religioso. La relación Dios-hombre, no es resultado del yo subjetivo, del que surgiría como una "objetivación» la idea de Dios. Es cierto que el acto religioso tiene una dimensión inmanente, sin embargo «solamente es posible comprender su existencia si se acepta la realidad de las formas objetuales a las que tiende» ${ }^{286}$. Esta perspectiva, sin embargo, ya no puede ser fenomenológica aunque no lo subraye $M$. Scheler, ya que la fenomenología prescinde de toda urealidad».

Por otra parte, los actos religiosos tienen una legitimidad autónioma, que no puede inferirse de una causalidad empírico-psicológica. Esta legitimidad es de matiz noético, no psicológico ${ }^{287}$.

Los "sentimientos» son un elemento concominante del acto religioso, pero nunca puede ser reducido a éstos, al no ser un "fenómeno fundamental psíquico» ${ }^{288}$, como tampoco son especies o combinaciones de otras clases noéticas de acto p.e., lógicos, éticos, estéticos, etc... Esto es evidente dada la originalidad y autonomía de la Religión.

El pensamiento scheleriano, se muestra contundente en este punto y dada su importancia le ofrecemos textualmente:

«Para toda región del ser, existen nexos esenciales, evidentes y materiales (a priori), frente a cualquier experiencia, positivo-inductiva y una clase de actos que corresponden legítima y esencialmente a su posible intuición... por consiguiente existen también axiomas evidentes, objetivamente válidos $y$ categorías de intuición y conocimiento religioso, que sólo pueden sernos evidentes, si realizamos en nosotros el ser eterno de estas intuiciones, si despertamos en nosotros el acto religioso y nos ejercitamos en una cosmo-visión religiosa. En el pensamiento religioso, existe pues, una lógica del ser, que, como toda lógica, incluye en sí la lógica formal y la teoría de los objetos y que al mismo tiempo va más allá de los principios de éstas, llegando a las evidencias óntico esenciales de la esfera del ser y del objeto religioso a la que sería imposible llegar por otra esfera de ser no-religiosa» ${ }^{289}$.

En el acto religioso, verdaderamente tal, está comprometido todo el hombre, de aquí que $M$. Scheler rechace fundamentalmente los intentos de concebir lo Religioso, exclusivamente desde la vertiente del entendimiento (Hegel), de la voluntad (Kant) o del sentimiento (Schleiermacher). La concepción scheleriana, pı esenta un «engagement» total del hombre: «En la totalidad indivisa de la persona, en su mismo núcleo... reside lo más profundo en

286. Ew. M. 242.

287. Ibd.

288. Ew. M. 244.

289. Ew. M. 273. 
nosotros, aquel maravilloso resorte, habitualmente inadvertido y olvidado regularmente, que actúa siempre de una manera constante, elevándonos a lo Divino, por encima de nosotros mismo y más allá de todo lo finito» ${ }^{290}$.

En el acto religioso - como compromiso total del hombre- se pueden distinguir según esto:

a) un elemento intelectual por cuanto la óntica esencial de lo divino, precede siempre al acto religioso. Al ser anterior el ser al conocimiento del mismo «los objetos de la esencia de lo divino, son algo originariamente dado a la conciencia humana» 291 ;

b) un elemento volitivo: de cara a lo Divino, la voluntad humana viene a ser el núcleo central. Mientras no exista el acto volitivo permanece el hombre impermeable a Dios: ya se sabe, no existe un ciego más ciego, que el que no quiere ver;

c) un elemento afectivo: ya que el encuentro personal con lo Divino se efectúa dentro de un plano emocional: «Nuestra relación emocional, con lo trascendente, precede a toda formación de ideas, la guía y la dirige»" ${ }^{292}$.

d) un elemento activo: el acto religioso es una reacción a la acción originaria de Dios, por eso la experiencia religiosa aunque esencialmente receptiva, es una pasividad activa; la teopatía ha de estar unida a una verdadera antropogénesis.

En el acto religioso, se cruzan, pues, todos los elementos constitutivos del hombre, en cuanto persona-espiritual. No se puede cuadricular a éste para entender el acto mismo de la experiencia religiosa. Es un verdadero engagement del hombre. Por esto es el acto religioso, el acto por excelencia del hombe, constitutivo de su esencia ${ }^{293}$; por esto el hombre sólo se puede comprender desde la esfera del Absoluto ${ }^{294}$. El hombre no tiene ninguna elección posible entre la aceptación o negación de la esfera del Absoluto, ya que es algo originario en la conciencia humana. Solamente puede elegir el hecho de que esta esfera esté llenada por Dios, o por un ídolo. En este caso, el camino que lleva al verdadero Dios, es la des-ilusión. Entonces aparece el verdadero orden del ser ante la razón y el del valor ante el principio cognoscitivo del mismo: el corazón. Aquí se vuelve a establecer el verdadero "ordo-amoris», del que es expresión concreta el acto religioso. Con esto nos encontramos con otra dimensión: el amor:

Esta dimensión inmanente es completada mediante la relación del acto con su objeto intencional. Ambos, forman una unidad de la que surge el acto religioso como trascendente inmanente.

El acto religioso, tiene además una dimensión interna-individual y

290. Ew. M. 103.

291. Ew. M. 159.

292. Ew. M. 350.

293. Ew. M. 171.

294. Fth. 293. 
externa-social ${ }^{295}$. Precisamente porque el acto religioso es el más personal del hombre, es un acto que ha de llegar a su objeto por medio de una forma comunitaria ${ }^{296}$. M. Scheler conecta aquí con el pensamiento de la tradición cristiana: «Unus christianus-nullus christianus» ${ }^{297}$.

Esta dimensión social del acto religioso, no solamente está condicionada porque el "yo» auténtico ha de aparecer siempre en la forma concreta de un «nosotros» ${ }^{298}$, sino y ante todo, por «la plenitud inagotable de Dios», a la que sólo puede acercarse un «nosotros» de tiempo y pueblos ${ }^{299}$.

Aquí aparece el acto religioso en su historicidad en su relación temporal. M. Scheler, subraya estas dos propiedades frente a la teología natural de la filosofía de la llustración. La historicidad connota a un suceder en el tiempo y la relación temporal a un realizarse en la historia.

La insuficiencia del acto religioso considerado en su singularidad, para adentrarse en profundidad sobre el horizonte de lo Divino enfrenta el pensamiento scheleriano con la actitud «mística» y «racionalista»: «ambas tienen como característica el intimar con demasiada facilidad con Dios: ésta por medio de conceptos que atomizan a Dios, aquélla con el sentimiento, en el que parece explayarse Dios. A las dos les falta un respeto reverencial, e.d., aquella actitud en la que se percibe a Dios como ser eminentemente oculto» ${ }^{300}$.

Hemos visto, hasta ahora, el carácter originario del acto religioso - dada la conexión esencial con su objeto y su pertenencia a la misma esencia del hombre-, nos hemos asomado a su estructura interna y hemos reseñado algunas propiedades del mismo; ahora bien, aunque el acto religioso pertenezca al constitutivo esencial del hombre, aunque sea en sí «una dote necesaria del alma humana espiritual» ${ }^{301}$, solamente puede ser realizado por el hombre «bajo ciertas condiciones» ${ }^{302}$.

M. Scheler se encuentra con esto en abierta oposición con H. Scholz ${ }^{303}$. Está de acuerdo con él en que la experiencia religiosa tiene una gráfica caprichosa, a veces clara y otras un tanto diluida; también en que puede ser excitada con determinados métodos técnicos; incluso concede a $\mathrm{H}$. Scholz que ciertas predisposiciones, pueden obstaculizar totalmente su posible realización. Sin embargo duda de que «ciertas predisposiciones positivas (como sucede p.e., cuando se trata del talento) han de condicionar la experiencia religiosa, de modo que pueda decirse que un hombre no es religioso como podría afirmarse que no tiene cualidades musicales» ${ }^{304}$.

295. Cfr.: Ew. M. 258-261.

296. Ew. M. 261.

297. Ew. M. 260.

298. Cfr.: Symp., 228-287.

299. Ew. M. 19.

300. U. d. W. 26.

301. Ew. M. 261.

302. Ew. M. 21.

303. Religionsphilosophie, Berlin: Elwert und Meurer 1922.

304. Ew. M. 23. 
Para M. Scheler un Dios que permitiera que un grupo de hombres tuviera más aptitud que otro para la experiencia religiosa no sería Dios ${ }^{305}$.

En oposición a H. Scholz, propugna M. Scheler que ula experiencia del contacto personal con Dios en el núcleo de la persona humana y espiritual se da siempre y de una manera necesaria, si se cumplen dos condiciones, una negativa y otra positiva» ${ }^{306}$.

La condición negativa, la apellida Scheler «des-ilusión acerca del ídolo» y la hace consistir en «la eliminación del centro de la esfera dada originariamente a la conciencia humana como esfera del absoluto, de todas las cosas y valores finitos juntamente con la re-moción de la propia identificación, consciente o inconsciente con estos objetos finitos de fe y amor» ${ }^{307}$.

El contenido de esta condición es platónica: se necesita una

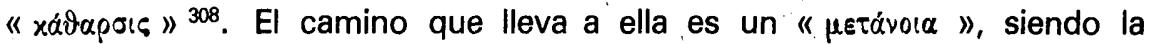

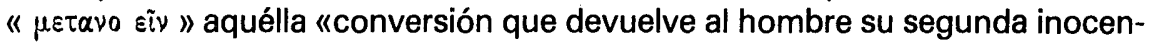
cia en una completa abertura a Dios.

La condición positiva consiste en que ula misma persona espiritual ly consiguientemente sus actos) actúe no condicionada por otra cosa sino sólo por sí misma, frente al principio vital (y sus funciones)» ${ }^{309}$. Esta aptitud es fundamental. La libertad de elección es una propiedad del hombre por la que éste se encuentra en la encrucijada de afirmar o negar la posibilidad de existencia auténtica que, como hemos visto, consiste en una antropogénesis, que se da por la irrupción de Dios en el hombre mismo.

Dadas estas dos condiciones, se realiza el acto de la experiencia religiosa, como un encuentro entre Dios y el hombre, resultado de este encuentro es el contacto vivencial con Dios, la «inmediata intuición». (Schau) de Dios.

Ahora bien, ¿cómo se puede entender esta «inmediatez» en el conocimiento de lo divino, sabiendo que $M$. Scheler rechaza directamente toda postura ontologista? ${ }^{310}$. Para explicarla no podemos defender aquí la existencia de un coeficiente histórico augustiniano en $M$. Scheler, ni tampoco de un augustinismo con la impronta de la época de Nietzsche.

Según la tradición augustiniana, a la que apela por otra parte frecuentemente $\mathrm{M}$. Scheler ${ }^{311}$, el carácter inmediato del conocimiento religioso está especificado por su peculiaridad concreta: la presencia de lo divino aparece también en ausencias. Es algo paradójico: presencia del ausente y «aún no» del presente. La experiencia religiosa es un padecer inmediato lo desconocido y en esto se diferencia, precisamente, de la mística: Dios permanece como el

305. Ew. M. 24.

306. Ew. M. 28.

307. Ibd.

308. Cfr.: Fedón, Buenos Aires: Aguilar 198\%, 670.

309. Ew. M. 28.

310. Ew. M. 14.

311. Ew. 265; Soz. Welt. 93-94. 
"Desconocido», el «Buscado» aunque esté presente. Lo divino es simultáneamente lo más cercano desde una vertiente óntica (intimior intimo meo), aunque desde el plano ontológico sea lo más lejano. La presencia y la ausencia de Dios en la tradición augustiniana es como una mística de cercanias y distancias, como una mística en la noche.

Sin riesgos de ningún ontologismo estaría así explicada la «inmediatez» del conocimiento de lo divino... pero no en M. Scheler.

Tampoco creemos se pueda explicar esta «inmediatez» interpretándola en un sentido meramente fenomenológico, deviniendo de la intencionalidad del acto religioso, como hace concretamente E. Przywara ${ }^{312}$. En el acto religioso, como veremos en el capítulo siguiente, hay toda una complejidad de dimensiones.

La «inmediatez» del conocimiento está determinada propiamente en el pensamiento scheleriano por el hecho de que todo conocimiento es una «relación óntica» que implica, por tanto, una «participación en el ser del otro.» ${ }^{313}$.

312. Zu M. Schelers Religionsauffassung, 25.

313. Wi. Ges. 203. 


\section{CAPITULO SÉPTIMO}

\section{LA ACTITUD FENOMENOLÓGICA DE M. SCHELER Y EL PROBLEMȦ DE LA EXISTENCIA DE DIOS.}

Reconocer, en principio, la complejidad temática de este capítulo, es para nosotros condición esencial de su planteamiento $y$ de todo intento que se dirija objetivamente a encontrar una respuesta adecuada.

El planteamiento simple y la respuesta parcial no pueden tener ninguna validez de cara a la objetividad.

De aquí parte precisamente la crítica de J. Llambias de Azevedo -única cuestión en la que por cierto estamos de acuerdo con él - a la obra, por lo demás tan meritoria de $M$. Dupuy ${ }^{314}$, resumida en esta afirmación: «M. Dupuy... no ha tenido en cuenta estas distinciones... por lo cual sus conclusiones son demasiado globales y no pueden reducir las contradicciones y las negligencias de Scheler a sus verdaderos límites» ${ }^{315}$.

$\mathrm{Si}$ queremos juzgar con exactitud la postura de M. Scheler en esta problemática concreta tenemos que distinguir en él entre «quaestio iuris» $y$ «quaestio facti».

Con respecto a la primera, el pensamiento scheleriano no ofrece ninguna dificultad, es claro y explícito.

Al hacer como un balance de El formalismo en la ética y la ética material de los valores afirma tajantemente: «En todo este trabajo no se habla para nada de una posición real de la esencia de Dios» ${ }^{316}$.

En De lo Eterno en el hombre es, incluso, más explícito:

"La fenomenología esencial - por tanto la fenomenología esencial de la religión - aunque no autoriza nunca la posición real de un objèto afirmada como verdadera, pues procede precisamente con la exclusión consciente del

314. La philosophie de la Religion chez M. Scheler, Paris: P.U.F. 1959.

315. J. Llambias de Azevedo, Max Scheler. Exposición sistemática y evolutiva de su Filosofia. Buenos Aires: Nova 1966, 328 nota.

316. Eth. 395 nota. 
coeficiente de existencia de los correspondientes objetos, sabe «a priori» que las «conexiones esenciales» logradas por ella, al ser válidas para la esencia de los objetos, valen también para todos los posibles objetos contingentes de la «esencia» correspondiente e.d., los juicios sobre ella son verdaderos. Pero la realidad misma «según» y «conforme» esas conexiones esenciales sólo la puede "poner» una especie de experiencia contingente... concretamente (tratándose de objetos de la esfera suprasensible) la Metafísica o la autocomunicación positiva de Dios e.d., la «revelación», cuya aceptación tiene lugar exclusivamente en actos de fe» ${ }^{317}$.

Es evidente, pues, como simple consecuencia fenomenológica, que la actitud fenomenológica de M. Scheler excluye "legítimamente» («quaestio iuris») toda "posición real» de la idea de Dios.

Ahora bien, el excluir de derecho esta problemática no implica que «de hecho» («quaestio facti») M. Scheler prescinda de la «posición real» de la esencia de Dios.

$Y$ es aquí donde reside precisamente la complejidad del pensamiento scheleriano.

Para explicar este «hecho» no podemos aceptar en ningún sentido ni la interpretación general ni las razones de la misma que presenta J. Llambias de Azevedo:

«M. Scheler describe el objeto religioso tal como se da en el «acto religioso natural...» «Natural» significa aquí no sólo lo opuesto a lo sobrenatural en el sentido del acto en que se recibe el contenido de la revelación positiva, sino también «actitud natural» como opuesta a "actitud fenomenológica». Esra interpretación se confirma: primero, porque Scheler sostiene que el acto religioso es ejecutado por todo el hombre $y$ todo hombre no es fenomenólogo $y$ segundo, porque al referirse a estos actos los determina como aquéllos en que «la conciencia religiosa vive ingenuamente como en su milieu» ${ }^{318}$.

Sinceramente creemos que la complejidad del pensamiento de M. Scheler raya en este punto con la contradicción -como veremos-. De ahí el problema.

Pero nunca es solución aceptable de un problema... negarlo. Y esto es lo que involuntariamente hace J. Llambias de Azevedo.

No sólo niega prácticamente la existencia del problema con su interpretación al afirmar que $M$. Scheler ni advierte cuándo la asume (la actitud fenomenológica) ni cuándo la relega») ${ }^{319}$, sino que reduce a la nada el principio fundamental de la fenomenología scheleriana, destacado insistentemente por $M$. Scheler, según el cual «existe una correlación legítima y esencial entre el acto religioso y el objeto religioso» 320 .

317. Ew. M. 13-14.

318. J. Llambias de Azevedo, Max Scheler. 325-326.

319. J. Llambias de Azevedo, I.c., 326.

320. Ew. M. 277-273. 
No comprendemos que basándose en una palabra («natural») de sentido sin duda polivalente, pueda desconocer que M. Scheler pretende ante todo ofrecer una descripción fenomenológica del acto religioso, sin lograrla, al dar entrada a datos extrafenomenológicos del conocimiento religioso.

Pordríamos multiplicar los textos a este respecto:

«Esto es lo que puede decirse - según creo- en virtud de la descripción esencial del acto religioso" ${ }^{321 .}$.

«El acto religioso en cuanto especie esencial de actos...»" ${ }^{322}$.

«El acto religioso, si no va precedido de una óntica esencial de lo Divino lleva a un absoluto subjetivismo» ${ }^{323}$.

Por otra parte $\mathrm{M}$. Scheler asigna al acto religioso las características dimanantes de la fenomenología de los actos en general:

a) El trascender al mundo de su intención,

b) La posibilidad de llenarse sólo con lo divino,

c) La posibilidad de llenarse con un ser divino que se abra a sí mismo en una auto-manifestación ${ }^{324}$.

Estas dos últimas características tienen su razón de ser en que dada la correlación entre objeto y acto, éste participa de la región esencial del objeto correspondiente.

J. Llambias de Azevedo apoya también su interpretación en que para $\mathbf{M}$. Scheler el acto religioso "es ejecutado por todo el hombre..." y no todo el hombre es fenomenólogo. La ingenuidad de la interpretación es casi irritante.

No tiene en cuenta la peculiaridad del pensamiento antropológico de $\mathrm{M}$. Scheler que - como veremos en la Tercera Parte - cuando habla del hombre se refiere a la «persona espiritual», que como eterno en el hombre, tiene su sentido precisamente en su inserción en la Esfera del Absoluto.

Hasta ahora hemos visto que en $M$. Scheler hay que distinguir entre "quaestio iuris» y "quaestio facti».

Con respecto a la primera hemos constatado que no puede existir ninguna dificultad interpretativa ya que expresamente se pone entre paréntesis la "posición real» de algo con «esencia divina».

Ahora bien, en la «quaestio facti» podemos apreciar una diferencia clara entre las obras de El formalismo en la ética y la ética material de los valores y De lo Eterno en el hombre.

En la obra ética de $M$. Scheler el mundo de los valores se fundamenta en

321. Ew. M. 243.

322. Ew. M. 244.

323. Ew. M. 285.

324. EW. M. 244-245. 
el valor de lo absolutamente santo. Pero ¿cómo puede pensarse que toda la vida moral pueda asentarse en una «esencia fenomenológica» aunque sea de lo santo absolutamente?

Sin duda que $M$. Scheler supone más de lo que pudiera permitir su actitud fenomenológica. Si se coloca la dimensión real de lo absolutamente santo en un segundo plano, y más si se prescinde expresamente de ella pierde la obra ética su propio sentido. Bien pudiera decirse que si no parte abiertamente de la uposición real» de lo absolutamente santo, tampoco la excluye.

Esta afirmación puede tener su punto de apoyo en la abierta contradicción de los siguientes textos:

«En todo este trabajo no se habla para nada de una posición real de la «esencia» de Dios»" ${ }^{325}$.

«Si se ha puesto ya la realidad de Dios... puede y debe ser capaz el hombre de la intuición ética... en cuanto «iluminación natural» del hombre por parte de Dios» ${ }^{326}$.

No hay que pensar que ambos textos están distantes en el tiempo.

El estudio recogido por los Escritos póstumos y que lleva como título La Esfera del Absoluto y la posición real de la idea de Dios. está escrito por los años 1915-1916 ${ }^{327}$ precisamente cuando $M$. Scheler está publicando El formalismo en la ética y la ética material de los valores ${ }^{328}$.

Si nos referimos ahora a cómo procede «de hecho» $M$. Scheler frente al problema de la existencia de Dios en la obra De lo Eterno en el hombre creemos que hay que distinguir nuevamente dentro de la esfera del acto religioso entre «consistencia» (Bestand) y «contenido» (Gehalt) del mismo.

Es la misma fórmula que él propone y que nos ha servido para solucionar cierta confusión rayana con lo contradictorio en lo referente a la «consistencia» de la esfera del Absoluto y al "contenido» de la misma en virtud de sus «diferentes formas de manifestación».

Sinceramente creemos que aquí está la clave de la interpretación auténtica.

Podría censurarse, quizá, en $\mathrm{M}$. Scheler la ausencia de una exposición sistemática, matizada, pero entonces no sería $M$. Scheler.

Si existe una correlación esencial entre objeto y acto, si el acto participa de las peculiaridades esenciales de la región esencial del objeto, si el objeto tiene una "consistencia» y un "contenido», el acto ha de manifestar la estructura esencial del objeto. Es obvio que pueda considerarse, pues, en sus dos vertientes.

Ahora bien, si las «formas de auto-manifestación» del objeto religioso

325. Eth. 395 nota.

326. Nachl. 198.

327. Nachl. 512.

328. 1913-1916. 
van más allá de toda intención fenomenológica al estar insertadas en las coordenadas de lugar y de tiempo, también el «contenido» del acto religioso.

En este nivel es todo un principio fenomenológico que «la posición fáctica... de algo ya determinado esencialmente se fundamenta en la experiencia accidental y fáctica y no... sobre la experiencia fenomenológica» ${ }^{329}$.

Aquí se mueve igualmente $\mathrm{M}$. Scheler más allá de toda actitud fenomenológica.

Pero con esto no han terminado los problemas interpretativos. Podríamos hablar hasta aquí de planteamiento o enfoque.

III

Si el acto religioso en su "consistencia» (Bestand) tiene como correlato esencial el objeto religioso, en su «contenido» (Inhalt) es «la revelación... de un real de la esencia de Dios» correlato intencional del mismo ${ }^{330}$.

Por este motivo puede afirmar M. Scheler: «Pertenece a la esencia de la conciencia finita el tener una esfera del Absoluto y el llenar esta esfera con un cierto contenido"s ${ }^{331}$.

Si preguntamos ahora: «¿Puede inferirse de la existencia de los actos religiosos la existencia de Dios?» ${ }^{332}$, la respuesta ha de ser clara: como el acto religioso puede tener un correlato esencial (la esfera del Absoluto) y un correlato esencial-fáctico - dimanante, por una parte de la "consistencia» apriórica de su objeto (esencial) y por otra de su manifestación (fáctica) - según desde qué ángulo de visión presentemos la pregunta tendremos una u otra respuesta.

Dentro de una vertiente exclusivamente fenomenológica, desde la atalaya de la «consistencia» tanto de la esfera del Absoluto como del acto religioso la respuesta es clara: «Si tenemos la esencia de un ser personal todo-amor como dato apriórico, es evidente que no podemos decir nada sobre su ser-real o no-real» ${ }^{333}$.

Ahora bien, si presentamos la pregunta desde el ángulo del "contenido» tanto de la esfera del Absoluto, en virtud de sus «diferentes formas de automanifestación» como del acto religioso en que se manifiestan como correlato intencional e.d., más allá de toda actitud fenomenológica, aparece igualmente clara la respuesta de $M$. Scheler: "La esencia apriórica de la divinidad -en contraposición de los objetos reales de esencia finita - excluye que lo (eventualmente) real de esta esencia se «deje conocer como real por actos espontá-

329. Nachl. 181.

330. Ew. M. 249.

331. Ew. M. 262.

332. Ew. M. 254.

333. Nachi. 194. 
neos de la persona o razón finita. Dicho de forma positiva: Si existe algo de esencia divina en realidad hay sólo una forma según la que su realidad pueda llegar a las personas finitas: que se dé a conocer espontáneamente a estas personas (o a alguna de ellas)... Este darse-a-conocer sólo puede significar la auto-manifestación de la personan" ${ }^{334}$.

Tiene capital importancia para el objeto de nuestro trabajo la precisión de la vivencia de esta «realidad, como "contenido de fe" ${ }^{335}$ del acto religioso.

En general podemos afirmar que existe una gran fluctuación en $\mathrm{M}$. Scheler de esta época - 1921 - en lo referente a la aprehensión de la vivencia de la «realidad». Sin embargo aparecen ya ciertos indicios que apuntan al momento volitivo en la aprehensión de la realidad; no despejan, es cierto, algunas dudas, sino contradicciones, ya que se muestra M. Scheler en este punto demasiado cauteloso en sus afirmaciones.

«El ser-real de algo... se da originariamente en la vivencia intencional de posibles resistencias de un objeto frente a una función espiritual volitiva en cuanto tal» ${ }^{336}$.

A pesar de esta afirmación no está muy claro, sin duda, su pensamiento.

Por una parte repite insistentemente - y según creemos en el sentido anteriormente explicado - que lo divino como real se da en el acto religioso de fe ${ }^{337}$.

Sin embargo el acto religioso de fe es diferenciado del de la voluntad: «Este acto es un acto sui generis y no puede subsumirse ni en la esfera de actos intelectuales no volitivos" ${ }^{338}$.

Esta irreductibilidad de los actos de fe a la esfera de la voluntad es indicio cierto de que $M$. Scheler fluctúa en su pensamiento sobre la aprehensión de este «real» de la esencia de Dios. Tenemos un ejemplo claro en la siguiente afirmación que encontramos en los «Escritos Póstumos»: «El ser-ahí de una esencia en la esfera del ser ideal es dado por posición, en la esfera real, limitada y relativa por la «fe» (belief), en la esfera del ser-ahí absoluto por la «fe» (faith) ${ }^{339}$.

Según esto podríamos afirmar que la vivencia de lo «real» de esencia de Dios en el acto religioso aparece por el momento en $\mathrm{M}$. Scheler en una cierta fluctuación entre inclusión o exclusión de la "vivencia de resistencia». M.

334. Nachl. 185.

335. Ew. M. 262.

336. Ew. M. 215.

337. Ew. M. 155-155, 165, 297; Nachl. 184-186.

338. Ew. M. 262; Cfr. Nachl. 241.

339. Nachl. 211. 
Scheler, pues, no tendría que modificar nada, solamente completar matizando, aunque, como veremos más adelante al precisar su aprehensión de la realidad, se abra a un «dualismo de actos» que tiene como vertiente objetiva el «dualismo ontológico».

De una parte y por ahora, sostiene $\mathrm{M}$. Scheler que todo acto religioso presupone un «contra-acto» por parte del objeto religioso ${ }^{340}$, llegando incluso a afirmar que «percibimos en la vivencia de resistencia de «algo»... la eficiencia de algo que re-siste» ${ }^{341}$.

Solamente pues en el sentido de un encuentro inmediato y no de una cognoscibilidad en general podríamos entender que el ser-ahí de un realsubstancial de la esencia de Dios se da en la experiencia positiva religiosa de su revelación, haciendo, precisamente, consistir la experiencia de resistencia con respecto al ser-real de esencia de Dios en el encuentro con su revelación.

Ya sabemos el sentido específico de todo "encuentro», presupone siempre un ir "en-contra». Una cuestión fundamental sería si toda resistencia experimentada es indicio de realidad o sólo la que tiene una estructura sensible. En el primer caso se podría hablar de la realidad de las alucinaciones.

De modo ulterior defiende $M$. Scheler que el ser-real de Dios en el acto religioso se logra «por un contacto personal de la experiencia del mismo núcleo de la persona» con lo divino ${ }^{342}$.

La explicación concreta de esta afirmación la encontramos en Esencia y formas de la simpatía: "La persona (espiritual) qua persona es un ser inobjetivable, exactamente igual que el acto (persona es tan sólo una ordenación arquitectónica, intemporal e inespacial de actos, cuya totalidad hace variar cada acto particular, o como yo suelo decir, persona es «substancia hecha-de actos»), un ser sólo susceptible de que se participe ónticamente en su ser-ahí por la co-ejecución (pensar, querer, sentir con otro, pensar, querer, sentir lo mismo que otro, etc.) $){ }^{343}$.

Incluso lo recalca $\mathrm{M}$. Scheler en una nota al mismo pasaje:

"Si se piensa a Dios como persona, el saber de esta persona no es tampoco concebible como saber de algo objetivo, sino sólo como cogitare, velle, amare «in Deo», e.d., como coejecución de la vida divina y un "oír» su palabra por medio de la cual él mismo atestigua su ser-ahí como persona» ${ }^{344}$.

$Y$ este es precisamente el sentido que tiene en $M$. Scheler la "fe», en cuanto contenido del acto religioso, en la que nos «encontramos» con el serahí de esencia de Dios: la «identificación» con él mismo ${ }^{345}$.

340. Ew. M. 248.

341. Ew. M. 215.

342. Soz. Welt. 41.

343. Sym. 241.

344. Ibd. nota.

345. Ew. M. 262. 
Así aparece en el pensamiento scheleriano una idea vertebral en toda su antropología: la «deificación».

$\mathrm{Si}$, como hemos visto ya, la actitud fenomenológica converge en la aspiración a «ser semejante a Dios» ${ }^{346}$, más allá de toda actitud fenomenológica nos encontramos nuevamente con este concepto que, en consecuencia necesaria, llegará a su plenitud en la filosofía final.

\section{$\mathrm{V}$}

Como resumen general de esta parte de nuestra investigación podemos afirmar que el pensamiento de $\mathrm{M}$. Scheler en torno al tema de Dios presenta datos fenomenológicos junto con otros absolutamente extrafenomenológicos procedentes del área de la «experiencia religiosa» e.d., del conocimiento religioso ingenuo.

La legitimidad de su actitud fenomenológica sólo puede circunscribirse a la "consistencia» (Bestand) de la «Esfera del Absoluto» y a la «eidología esencial» (Wesensontik) de la misma.

Por otra parte, al darse una correlación esencial (Wesenszusammenhang) entre determinadas clases de objetos y sus actos respectivos, la legitimidad de su actitud fenomenológica en lo referente al «acto religioso» sólo puede limitarse a la "consistencia» (Bestand) del mismo, pero nunca a su "contenido" (Inhalt). Si éste en M. Scheler está determinado por la experiencia religiosa, hemos de subrayar que ésta no puede pertenecer en ningún sentido a la esfera fenomenológica.

Fenomenológicamente, pues, aparece la «esfera del Absoluto» en su «ser-así», en su «deitas». En la etapa final de su filosofía al enfocar el tema de Dios - según el «sistema de conformidad» programado en De lo Eterno en el hombre - desde una perspectiva metafísica, se destacará - por cuanto se apoya como hemos visto ya en la eidología - , la «deitas» (Geist), y al mismo tiempo - al depender de los datos de las ciencias positivas y en cuanto Realwissenschaft - el momento de la "realidad», que al estar determinada por el «impulso» (Drang) tendrá como simple consecuencia filosófica el dualismo metafísico (Gesit-Drang) dentro del mismo Ser Supremo.

\section{OBSERVACIONES CRÍTICAS}

El sistema fenomenológico-religioso de M. Scheler ha levantado una polvareda de polémicas.

Nos llevaría muy lejos la simple historia de esta polémica. Sólo queremos constatarla circunscribiendo nuestra intención, más bien, a subrayar alguna

346. Ew. M. 86. 
de las deficiencias importantes para el objetivo de nuestra investigación y a destacar ciertos inicios germinales de la concepción scheleriana que irrumpirá en su filosofía final.

\section{A. Ausencia del momento gnoseológico:}

Aunque, en principio, M. Scheler es víctima de su división fundamental entre el ser-así y el ser-real, que aparecerá al final como dualismo metafísico de espíritu-impulso, no creemos se pueda censurar de "formalista» la concepción scheleriana de la esfera del Absoluto: es independiente de toda formalización intelectual, es irreductible a cualquier orden noético. Sin embargo ¿cómo puede ser consciente el hombre de su objetividad? ¿cómo puede saber que no es resultado de un espejismo, ni de la pura subjetividad? No estimamos suficiente la respuesta de $M$. Scheler de que sea «index veri et falsi».

\section{B. Infravaloración de la metafísica:}

No es feliz, al ser inexacta, la apreciación de $H$. Fries, de que para $M$. Scheler «La Religión metafísicamente hablando carece de importancia, igual que es absolutamente irrelevante la metafísica desde un ángulo religioso» ${ }^{348}$. Hay que distinguir el orden intencional y el fáctico en el sistema filosóficoreligioso de $\mathrm{M}$. Scheler.

En principio., el acto religioso es concebido como «Gemütsakt» y como "Vernunftsakt» y se impugna decididamente el conocimiento religioso que no esté anclado.en las.profundidades metafísicas igual que el metafísico que no se fundamente en el religioso. Por otra parte, el sistema filosófico-religioso de M. Scheler, es un «sistema de conformidad» en el que Religión y metafísica están en una íntima unidad religiosa: La posesión adecuada de Dios se realiza sólo en la conjunción de los dos momentos - religioso y metafísico.

Sin embargo, - y como ya lo hemos visto anteriormente - esto es prácticamente un programa, en la obra De lo Eterno en el hombre, un plan que sólo se queda en maqueta de exposición. $Y$ no se piense que este hecho es el resultado de una simple omisión; es más bien, fruto de una convicción que subestima el valor funcional de la metafísica bajo dos aspectos: en cuanto al contenido de su objeto y en cuanto a su capacidad.

Si M. Scheler afirma concretamente que la metafísica no puede llegar al conocimiento de Dios como persona, ello se debe, en último término no solamente a que la persona es únicamente cognoscible en cuanto se da a conocer, sino porque es concebida esencialmente como «substancia de actos» que nunca pueden desempeñar las funciones de "objeto" ya que se manifiestan de una manera exclusiva en la co-ejecución de los mismos. Esta exclusividad, tiene aquí caracteres de infravaloración.

348. Die Katholische Religionsphilosophie der Gegenwart 149. 
La significación óntica ha de ser la misma en la Religión, que en la metafísica, puesto que el ser por excelencia de la metafísica ha de poseer la plenitud interna de ser en el mismo núcleo personal. No se trata de ignorar la diferencia intencional existente en la Religión y en la metafísica, pero tampoco de interpretar un «no-estar-desarrollado», un «no-ser-explícito», por una incapacidad esencial.

Por otra parte, creemos sencillamente errónea la actitud de M. Scheler, frente a la capacidad metafísica, igual que el proceso que converge en esa actitud: «Si prescindimos de las determinaciones formales, ontológico-axiológicas de su esencia (Ens a se por excelencia, Valor absoluto por antonomasia) el ser absoluto tiene un valor de probabilidad igual a cero. Esto significa que existe ciertamente una metafísica, pero no una metafísica material del ser absoluto") ${ }^{349}$.

Para M. Scheler, la metafísica se basa en los conocimientos reales de las ciencias positivas. Su conocimiento es la conclusión de dos premisas, siendo la mayor la ontología esencial y la menor la ciencia positiva. En rigor lógico (peiorem sequitur semper conclusio partem) los conocimientos metafísicos «tienen constantemente un valor hipotético» ${ }^{350}$ y de aquí el carácter esencial de probabilidad de la metafísica.

Dada esta infravaloración de la metafísica, tan injustificada como inaceptable, y partiendo de que no existe un fundamento más firme de la Religión que ella misma, lo que en principio fue orientación objetiva se queda en una simple descripción fenomenológica parcial: M. Scheler hace en De lo Eterno en el hombre pura y sola hierología, ya que prescinde de dos momentos esenciales - o al menos integrales-: el gnoseológico, que analiza y purifica y el metafísico, que profundiza y ancla.

\section{Mezcla indiferenciada de lo "natural» y "sobrenatural»}

Existe en M. Scheler, una inclinación al "Tradicionalismo»: "Todo saber cerca de Dios, es a través de Él», siendo por esta causa el conocimiento religioso más originario que el metafísico. Los «homines religiosi» - término de la manifestación divina - constituyen el punto de partida de toda filosofía de la religión. Pero los «homines religiosi» no se mueven en un plano absolutamente natural, al menos están en un espacio intermedio. El orden natural y sobrenatural, aparecen ya aquí un tanto diluidos.

M. Scheler, ignora - o aparenta ignorar - la dimensión sobrenatural de algunas de sus afirmaciones. Nos referimos concretamente al hecho de la experiencia religiosa, en el sentido auténtico scheleriano, como «tercer principio de conocimiento" de lo Divino. Aquí es $\mathrm{M}$. Scheler, víctima de una confusión manifiesta: entre lo perteneciente al hombre "de iure» y "de facto».

349. Ew. M. 300.

350. Ew. M. 292. 

Esta misma dimensión aparece también en el concepto de «coejecución».

Dios es "ser en acto", tanto en cuanto ser absoluto como en cuanto persona, y si la persona no puede ser aprehendida sino es mediante la «coejecución» de sus actos, tampoco Dios. M. Scheler llega, incluso, a afirmar que el acto co-realizado por el hombre «es idéntico en cuanto a su contenido» con el realizado por Dios ${ }^{351}$.

Ya hemos visto, también, cómo el hombre en la «actitud fenomenológica» tiende a "ser semejante a Dios» ${ }^{352}$, igual que hemos podido constatar que en el acto religioso se opera una verdadera «deificación»" ${ }^{353}$.

Bien podríamos decir que con los conceptos de «participación, «coejecución», "deificación», borra M. Scheler del horizonte esa raya profunda de diferencia ontológica entre Dios y el hombre. No sólo reduce distancias, sino que cree capaz al hombre de franquear fronteras originariamente vedadas.

En la Tercera Parte volveremos detenidamente sobre esto.

Insistimos en que la herencia augustiniana juega con muchas de estas vivencias, pero, como hemos dicho en las Notas Introductorias, está apoyada esencialmente en hitos, en arbotantes, en diques de contención que aseguran la estabilidad estructural del cosmos en su relación con Dios, estabilidad que se quiebra en M. Scheler por carecer de una frontera firme y claramente diferencial.

Es precisamente la ausencia del principio de «ejemplaridad», del principio de "analogía» la que hace que lo que podría haber sido un enorme arco abovedado distinto de lo infinito, pero apuntado hacia él, se quiebre diluyéndose en una prometeica y nietzscheniana fusión que acabará en el devenir renqueante tanto de Dios como del hombre en busca de su realización completa en la historia.

\section{E. Otros inicios germinales de la cosmovisión scheleriana final:}

Queremos destacar finalmente tres puntos, que expondremos muy brevemente ya que tendrán su explicación y culminación en la etapa final de $\mathrm{M}$. Scheler.

Estos puntos, junto a los conceptos anteriormente reseñados, son gérmenes sin duda del pensamiento scheleriano que aparecerá en su filosofía postrera.

1. Aunque M. Scheler subraya, en principio, la «creación del mundo» ${ }^{354}$ no es tan fácil su comprensión.

351. Eth. 230.

352. Ew. M. 86.

353. Ew. M. 262.

354. Ew. M. 225. 
Desde una perspectiva fenomenológica - como veremos más adelanteigual que corresponde a la persona finita un «mundo», le corresponde también a Dios, como persona infinita. A esto se reduce lo que podríamos llamar «inferencia trascendental» de la idea de Dios, aunque en $M$. Scheler no es propiamente una uinferencia» sino una correlación esencial.

Esta idea de Dios como correlato esencial del macrocosmos no parece estar en plena armonía con el concepto de «creación».

2. M. Scheler parece defender ya claramente la impotencia del espíritu: "Los actos del espíritu son en sí impotentes» ${ }^{355}$. Quizá le impida su actitud fenomenológica dedicarse al estudio de «lo real», quizá no tenga suficientemente elaborada su posible aprehensión, pero lo que es indudable es que, puesta la impotencia del espíritu, las consecuencias son incalculables.

3. Dentro de la aprehensión scheleriana de Dios como «logos guiado por el amor», se advierten sin duda ciertas posibilidades también de su metafísica final.

Aunque analizaremos el concepto de «amor» en $\mathrm{M}$. Scheler en nuestra Tercera Parte podemos anticipar aquí que para él es el amor el principio de movimiento del espíritu que está caracterizado por una absoluta «espontaneidad».

Las dimensiones de a-racional y pre-volitivo junto con la relación que le une al impulso - ciertamente no de "producción activa» sino de «limitación y selección»- ${ }^{356}$ le acercan notoriamente a la esfera del «Impulso» en la que se insertará prácticamente en la filosofía final, perdiendo su centralidad precisamente a manos de lo «impulsivo».

355. Ew. M. 234.

356. Sym. 201. 

«actitud fenomenológica») - , entre la constelación de los "valoręs» y el mundo de los «bienes» y de las «cosas» - (temática de la «Axiología») - , èntre lo "esencial-ideal-irreal» y lo "operativo-fáctico-real», al aparecer sobre el horizonte antropológico se disfraza de distinción entre el «hombre-(espiritual)persona» y el «homo naturalis».

Conscientes de que no pertenece al ámbito fenomenológico y de que, por tanto, hay que ponerlo "entre paréntesis» y marginarlo («epoché»), sin embargo, en aras de la arquitectura sistemática expositiva diseñaremos, en «negativo» al menos, el perfil "científico-natural» del hombre en M. Scheler, para destacar, al contraponerla, su «concepción fenomenológica del hombre como persona».

\section{EL «HOMO NATURALIS»}

Podría decirse que sobre el campo del hombre se está librando en silencio una gran batalla, entablada entre la Filosofía y las Ciencias y planteada en términos drásticos en el área metodológica. Lo que dirime en el fondo es la objetividad $y$, no en última instancia, el prestigio.

La complementariedad de perspectivas, la interdisciplinariedad de las Ciencias del Hombre habría que escribirla con caracteres de urgencia.

Esto es precisamente lo que $\mathrm{M}$. Scheler intentará muy esquemáticamente en "El puesto del hombre en el cosmo», que como se sabe tiene el sabor ácido de balance final.

Mientras tanto, y en etapa fenomenológica-intermedia de su pensamiento, M. Scheler, «ebrio de esencias» que diría Ortega y Gasset, destaca fuerte lo trasempírico del hombre, su vertiente «espiritual», llevando a cabo este objetivo de dos formas:

- de una manera directa, insertando la persona en Dios, por la participación en su esencia ${ }^{5}$ y por la co-ejecución de sus actos ${ }^{6}, y$

- de una forma indirecta, insertando al «hombre biológico-natural» en el mundo taciturno de las bestias.

«El hombre = homo naturalis es simplemente un animal, un pequeño camino vecinal de la vida dentro del campo de los vertebrados y concretamente de los primates. Su 'desarrollo' no ha ido más allá del mundo animal, sino que era, es y seguirá siendo animal»" ${ }^{7}$.

Elevando hasta el infinito la esfera del «espíritu» e infravalorando la vertiente «natural» del hombre $M$. Scheler abre un enorme hiato en la demarcación de lo humano, de consecuencias trascendentales ya que el hombre es "microcosmos» y «microtheos»: «Lo que apunta M. Scheler con su relativización sin límites de la apariencia externa del hombre va mucho más allá de to-

5. Ew. M. 285: Sym. 141.

6. Sym. 241, nota.

7. U. d. W. 190-191. 
das las exigencias de la antropogénesis, siendo sólo posible en el trasfondo apriórico de un dualismo radical que divide al hombre en vida y espíritu» ${ }^{8}$.

El «hombre natural» medido exclusivamente con el patrón de los valores biológicos no es en forma alguna el ser viviente «más valioso»" ${ }^{9}$.

En primer lugar no existe una diferencia ontológica, sino sólo de grado, entre el «hombre natural» y el animal: «Entre un chimpancé astuto y Edison (tomando a éste sólo como técnico) no existe más que una diferencia de grado, aunque ésta sea muy grande" ${ }^{10}$. El animal y el hombre constituyen una "continuidad estricta»" ${ }^{11}$ en la esfera biológica. La estructura y las funciones vitales psíquico-conscienciales pertenecen a la esfera vital psicofísica, existiendo entre ambas una "unidad funcional» ${ }^{12}$. Son dos caminos de acceso diferentes a un mismo proceso vital: "Lo que llamamos "fisiológico» y "psíquico» son, pues, dos perspectivas desde las cuales se puede considerar el único y mismo proceso vital. Hay una «biología desde dentro» y una "biología desde fuera» ${ }^{13}$.

Por otra parte, el «hombre natural» es un ser absolutamente indigente. Sus deficiencias instintivas, adaptativas e incluso regenerativas ${ }^{14}$ ha de suplirlas con la conducta técnica e inteligente, aunque no pueda impedir que éstas sean propiamente "virtud de una carencia»" ${ }^{15}$.

Ahora bien un ser que tiene necesidad de fabricar artificios para poder subsistir ontogenética y filogenéticamente no es sólo un "paso dado en falso», sino que manifiesta, incluso, su inferioridad frente a las bestias.

De aquí las expresiones de Scheler sobre el hombre: «callejón sin salida de la vida» ${ }^{16}$, «animal enfermo» ${ }^{17}$ animal "extraviado» ${ }^{18}$ "faux pas» ${ }^{19}$ "deserteur de la vida» ${ }^{20}$.

Por último, la separación radical entre la estructura biofísica y la esencia espiritual le lleva a consecuencias tan inevitables como grotescas, defendiendo que no existe una "forma igual de la naturaleza humana" ${ }^{21}$ ni en sentido empírico-psicológico, ni biológico, ni histórico, llegando a afirmaciones como

8. F. Hammer, Theonome Anthropologie? M. Schelers Menschenbild und seine Grenzen, Den Haag: M: Nijhoff 1972, 158.

9. Eth. 293.

10. Stell. 37, nota 1.

11. U. d. W. 194

12. Phil. W. 24.

13. Stell. 74.

14. M. Scheler llama al hombre «esclavo de la corteza cerebral» ya que tiene un poder regenerativo mínimo, apareciendo así el proceso vital como «petrificado» (Phil. W. 25).

15. U. d. W. 185.

16. Phil. W. 25.

17. U. d. W. 185.

18. U. d. W. 192.

19. U. d. W. 185

20. Phil. W. 78.

21. Phil. W. 122, nota 11. 
ésta: «Si mi perro apareciese y se ocultase intermitentemente en mi biombo, constatando yo que no quería ser descubierto... apostaría sin duda que era un hombre encantado" ${ }^{22}$.

M. Scheler llega, sin duda, demasiado lejos en la infravaloración psicofísica del hombre. La crítica sería demasiado fácil. Su intención se dirige, sin embargo, a separar irreductiblemente lo biológico-natural de lo espiritualpersonal. Sólo al concebir al hombre como centro de donde emergen los actos espirituales se abre todo un abismo entre el hombre-espíritu y el «hombre natural» clavado en el mundo taciturno de las bestias.

\section{EL ESPIRITU}

La fenomenología scheleriana del "espíritu» - constitutivo esencial del hombre - es sólo inteligible de forma adecuada en su conexión con las tendencias filosóficas de principios del siglo XX, contrarias a la ufilosofía de la vida».

Desde un principio traza vigorosamente $\mathrm{M}$. Scheler una línea ontológica diferencial entre "espíritu» y "vida», impugnando todo intento de explicación del espíritu como epifenómeno de la vida y defendiendo, en una continuidad absoluta de pensamiento, la irreductibilidad reciproca de ambos: "Rechazamos plena y totalmente el biologismo metafísico, e.d., la concepción del principio mismo del mundo como «élan vital», «vida...». El espíritu, el «nous» ni en cuanto "espíritu» cognoscente, intuitivo y pensante, ni en cuanto "espíritu» emocional y volițivo, es una «flor de la vida», una «sublimación de la vida», ninguna especie ni forma de leyes noéticas se deja "reducir» a leyes biopsíquicas de los procesos automáticos y (objetivamente) teleoclinos; cada uno de estos dos grupos es 'autónomo'»" ${ }^{23}$.

Si el hombre psicofísicamente es el «callejón sin salida de la vida», su espíritu» es la "salida» de ese callejón ${ }^{24}$.

Esta «salida» o «Ausweg» implica esencialmente la trascendencia y la actualidad, estando, pues, constituido el espíritu por estas dos características.

\section{A. TRASCENDENCIA}

"Espíritu» no significa para M. Scheler ser estático y cerrado en sí mismo, sino "movimiento-hacia» una meta que se encuentra fuera de sí.

Ya en el "Trabajo de Habilitación para la docencia» concibe M. Scheler el espíritu como «un apuntar más allá de sí»" ${ }^{25}$. Luego, en todos sus escritos subrayará esta dimensión trascendente de la fenomenología del «espíritu»:

\footnotetext{
22. U. d. W. 176.

23. Eym. 82.

24. Phil. W. 27.

25. Meth. 161.
} 
"La esencia del hombre está constituida por la intención de trascenderse a sí mismo y a todo lo vital» ${ }^{26}$. El hombre es únicamente "una cosa que se trasciende».

Precisamente por ser el hombre esencia espiritual y consistir ésta en pura trascendencia no es aquél ningún "estado firme» entre lo «natural» y «Dios»: "sólo es un "puente», un "entre», una "frontera», un "paso hacia adelante», una "epifanía de Dios» y un "eterno más allá» de la vida sobre sí misma» ${ }^{27}$. Aquí radica, precisamente para $\mathrm{M}$. Scheler, que el hombre por su espíritu sea, frente al «hombre natural», el "buscador de Dios», el "gesto de la trascendencia» y la "oración de la vida» ${ }^{28}$.

Ahora bien, esta trascendencia del espíritu le es dada al hombre como tal, pero no le es dada hecha, sino como quehacer.

En el trasfondo aparece de nuevo el hombre como ser esencial bifronte, que se encuentra ante una encrucijada de aiternativa: la posibilidad de remontarse hasta la misma esencia de Dios, mediante la co-ejecución de sus mismos actos o de enquistarse en el mundo taciturno de las bestias.

Si con anterioridad pudimos constatar que M. Scheler se desborda en la infravaloración de la estructura biopsíquica del hombre -igualmente exagera ahora la dimensión de trascendencia del espíritu:

"Una cosa que empieza a trascenderse a sí misma en una búsqueda de Dios ya es hombre, parezca lo que parezca» ${ }^{29}$.

La trascendencia del espíritu humano se nos presenta así de forma claramente discutible: «El concepto de trascendencia se vuelve problema en virtud de la tesis scheleriana de que el sujeto de esta trascendencia no está determinado ni psicológica ni biológicamente: no le pertenecen ni dedos, ni maxilares, ni, incluso, un alma racional (que Scheler distingue claramente del espíritu)» ${ }^{30}$.

Creemos que las expresiones de $\mathrm{M}$. Scheler al respecto, aunque controvertibles en sí ciertamente, se dirigen fundamentalmente a destacar el hiato profundo que existe en el hombre en cuanto ser-espiritual y ser-vital.

Ahora bien, como el «buscador de Dios» y el "homo naturalis» pertenecen constitutivamente al hombre en su ser bifronte, niega consecuentemente M. Scheler su «unidad óntica», habla de un ser corpóreo-psíquico y espiritual: no existe "un lazo de unidad substancial sino sólo dinámico causal» entre el espíritu y la vida, la persona y el centro vital ${ }^{31}$.

\footnotetext{
26. Eth. 293.

27. U. d. W. 186 .

28. Ibd.

29. U. d. W. 189

30. W. Hartmann, «Das Wesen der Person. Zur Personlehre Max Schelers» en: Salzburger Jahrbusch für Philosophie, (X-XI) 1966-1967, 153.
}

31. Sym. 83 


\section{B. ACTUALIDAD}

Con la trascendencia tiene una conexión inmediata la actualidad. Al no poder ser «substancia», esta trascendencia es sólo «en» actos y «por» actos. De forma ulterior, estos actos al distinguirse - como veremos - de las ufunciones» por su carácter eminentemente intencional, revierten nuevamente en la trascendencia. Entre actualidad y trascendencia existe, pues, un nexo intrínseco y esencial.

Ahora bien, si preguntamos cómo se diferencian las esencias de «actos abstractos» de las de los «actos concretos» que realizamos como nuestros, nos responde $M$. Scheler: "La persona es la única forma de existencia necesario-esencial del espíritu, en cuanto que se trata de un espíritu concreto» ${ }^{32}$.

32. Eth. 289. 


\section{CAPITULO SEGUNDO FENOMENOLOGÍA DE LA PERSONA}

Sin sortear el Scilla del asistematismo y el Caribdis de la perspectiva fenomenológica no es posible llegar a la comprensión adecuada de la persona en $M$. Scheler. En ningún sector de su pensamiento es tan válida la exigencia de Ortega y Gasset como en la doctrina scheleriana de la persona: «Es preciso completar su esfuerzo añadiendo lo que le faltó: arquitectura, orden, sistema» ${ }^{33}$. En sus escritos aparecen como "perdidos», sugeridos al margen, elementos descriptivos parciales, nunca una sistemática completa de la persona.

De ulterior, la actitud fenomenológica no tiene en absoluto como objetivo definir metafísicamente la persona, únicamente describirla como «hecho fenomenológico». Muchas de las objeciones y críticas, pues, surgen de ignorar expresamente esta perspectiva específica y asi es imposible que logren sus propósitos ${ }^{34}$.

\section{UNAS DELIMITACIONES PREVIAS}

La Fenomenología de la persona en $\mathrm{M}$. Scheler presupone el análisis de unos binomios de conceptos que resumiremos en los siguientes:

\section{A. ACTOS Y OBJETO}

"Acto» (intencional) y «objeto» son dos formas fundamentales de lo «dado" entre las que existe una correlación esencial y una irreductibilidad recíproca. La "esfera total de los actos» la condensa $M$. Scheler en el término «espíritu» ${ }^{35}$, diferencia ontológica entre el animal y el hombre.

Por su «espíritu» el hombre está «abierto al mundo» (weltoffen). Para el animal no hay objetos: Ser-objeto es «la categoría más formal del lado lógico del espíritu» ${ }^{36}$.

33. J. Ortega y Gasset, Obras Completas, 6 Ed., Madrid: Revista de Occidente 1966, 511.

34. Cfr.: E. Klumpp, Der Begriff der Person und das Problem des Personalismus bei $M$. Scheler, (No impreso), (Phil. Diss.) Tübingen 1951, 52 ss.

35. Eth. 388; Stell. 40.

36. Stell. 41 . 
La esfera de lo "objetual» presupone la del «espíritu», aunque el nexo esencial entre ambos no pueda entenderse en sentido idealista, como si «objeto» no significara más que la identificabilidad de algo por un «yo». Entre el "objeto" y el "acto» (intencional) se da una correlación esencial, una vinculación recíproca, de forma que uhan de corresponder objetos esencialmente idénticos a actos esencialmente idénticos también»" ${ }^{37}$. A la esencia de "objeto» pertenece la posibilidad de ser aprehendido por su acto correspondiente; pero ni un objeto puede ser realizado como acto, ni un acto puede convertirse en objeto: «A la esencia de los actos pertenece el ser vividos únicamente en la realización (Vollzug) y el ser dados en la reflexión» ${ }^{38}$.

Todo acto, pues, puede darse de forma dual: en su inmediata realización y en la reflexión ${ }^{39}$.

En la «reflexión», que es concomitante a la realización del acto o subsiguiente a ella, «se sabe» el acto, pero no está en forma alguna objetivado: "Objeto» y «acto» (intencional) son dos órdenes en correlación esencial y en irreductibilidad recíproca.

No es preciso apuntar que de la irreductibilidad entre "objeto" y "acto» brota un apretado de consecuencias de importancia capital para la comprensión de la «persona» en M. Scheler como «centro de actos».

\section{B. ACTOS Y FUNCIÓN}

En conexión, por una parte, y por otra, en polémica abierta con $F$. Brentano ${ }^{40}$ y C. Stumph ${ }^{41}, M$. Scheler propugna que no pueden confundirse los «actos», en cuanto realizaciones intencionales, y las "funciones».

Las «funciones» lo son del yo, no de la persona. Son psíquicas. Presuponen un cuerpo y un contorno al que pertenecen sus "manifestaciones». Las "funciones» son hechas en la esfera temporal fenoménica y hasta indirectamente mensurables en la subordinación de sus relaciones temporalesfenoménicas a las duraciones mensurables del tiempo de los fenómenos dados en ellas ${ }^{42}$.

Los «actos» no son ni físicos, ni psíquicos; no presuponen en su esencia ni cuerpo ni alma; no pueden ser objeto de la Psicologia Comprensiva, ya que son «espirituales» e.d., «inobjetivables».

37. Eth. 374; Ew. M. 277

38. Ibd.

39. Eth. 90; U. d. W. 234.

40. Psychologie vom empirischen Standpunkte, Leipzig: Dunker und Humblot 1874. 1906.

41. Erscheinungen und psychische Funktionen, Berlin: Vlg. für staatwiss. und Gesch.

42. Eth. 387. 


\section{ESENCIA ABSTRACTA Y CONCRETA DE ACTOS}

Frente a la esfera de «objeto» y «funciones», M. Scheler reconoce como lugar específico cie la "persona», la esfera de los actos. Dentro de la esfera esencial de los actos, distingue ulteriormente entre "esencias abstractasi y «esencias concretas».

Las esencias abstractas "son 'abstractas' - no como si fueran «abstraídas» - en el sentido de que reclaman un complemento de desarrollo, si han de existir. Frente a las esencias abstractas hay una segunda clase de esencias auténticas e intuitivas: las esencias concretas: para que una esencia de actos sea concreta «se precisa, para su ser dado pleno e intuitivo, la referencia a la esencia de la persona que es la realizadora de actos» ${ }^{43}$.

La diferenciación, pues, entre esencia abstracta y concreta es esencial para el planteamiento auténtico de la Fenomenología de la persona en M. Scheler.

La distinción entre «abstracto» y «concreto» no tiene nada que ver con la oposición entre la realidad concreta espacio-temporal y las abstracciones empíricas, al ser sólo válida en la esfera de las esencias.

Las esencias abstractas no tienen una autonomía óntica, exigen algo que las ilene, que las sirva de «complemento», apuntando, pues, de manera esencial a la esencia concreta.

Aunque según su materia son fenomenológicamente intuibles, propiamente son meros momentos de un complejo esencial, cuya autonomía óntica constituye la esencia concreta: «El «matiz rojo» de una superficie coloreada, p.e., de este paño, es intuitivo por completo, y como tal matiz rojo es también «individual», no únicamente por el complejo en que entra. Pero, a la vez, es algo abstracto perteneciente a la cosa concreta de esa superficie de tela» ${ }^{44}$. Las esencias abstractas pertenecen, pues, a las concretas «si es que han de existirn.

Las esencias concretas son ónticamente independientes, aunque «por el sólo hecho de que algo sea concreto no es considerado ya como 'real' $»{ }^{45}$.

A pesar de que suene a algo tautológico hemos de recalcar que las «esencias concretas» pertenecen al orden de lo «esencial», no al de lo «real».

Las esencias abstractas están implicadas en las concretas, siendo posible en la datitud de una esencia concreta la intuición de las esencias abstractas, en cuanto se fundamentan en ella. Todo ser, en su esencia, es primordialmente concreto. Concreción significa el carácter de esencia determinada y pertenece al «qué» de la realidad, no a la «realidad» del «qué».

Apliquemos, ahora, la distinción entre esencias abstractas y concretas a la esfera específica de las esencias de acto:

43. Eth. 383.

44. Eth. 383 , nota 1.

45. Eth. Ibd. nota 2. 
La fenomenología de los actos presenta las distintas clases, formas y direcciones de los mismos, sus conexiones esenciales, prescindiendo rigurosamente de los depositarios reales de esos actos y de su organización natural; tampoco considera si estas formas esenciales de actos han sido realizadas, ni por quién.

La actitud fenomenológica constata las posibilidades puramente esenciales y sus leyes, válidas para todo depositario y realizador de actos a priori.

Ahora bien, a toda esencia de actos pertenece esencialmente un «realizador» del mismo.

De aquí que ha de brotar una última pregunta:

"¿Qué es, pues, lo que, en entera independencia de la organización natural de sus depositarios (los hombres, p.e.), mediante cuya reducción llegan a destacar únicamente las esencialidades de los actos, vincula en unidad esas esencias diversas de actos $॥$ ? ${ }^{46}$.

Puesto que las esencias de actos y sus conexiones fundamentales son a priori, podemos, pues, preguntar: ¿qué realizador «pertenece» esencialmente a la realización de actos de esencias tan diversas? Sólo ahora "y no antes» ${ }^{47}$ se nos presenta la problemática de la persona.

Al no tener una autonomía óntica las esencias abstractas de actos hemos de preguntarnos qué pertenece aún a las distintas esencias de actos, a fin de que los actos puedan ser realizados.

La esencia concreta, exigida aquí, de las esencias abstractas de actos es la «persona».

El problema de la persona en M. Scheler se encuentra, pues, dentro de la región esencial de los actos, como «complemento» último de los mismos.

\section{LA PERSONA COMO CONCEPTO LÍMITE}

La fenomenología de los actos, sin variación fundamental de su actitud, ya que permanece en la esfera de las correlaciones esenciales - según lo que hemos expuesto en el parágrafo anterior - puede considerar las esencias de actos en su dimensión de abstractas, sin autonomía óntica, y puede también analizar la "vinculación en unidad» de las esencias abstractas de actos en la esencia concreta «persona», como realizadora de actos. La esencia «persona» "fundamenta», pues, las esencias abstractas de actos en el sentido de que éstas únicamente pueden representarse y aparecer en el ser-actual de aquélla. Así se logra la siguiente descripción fenomenológica, y no definición metafísica, de la persona:

«Persona es la concreta y esencial unidad entitativa de actos de esencia diversa, que en sí - no, por tanto quoad nos - antecede a todas las diferencias esenciales de actos, y èn particular a la diferencia entre percepción inter-

\footnotetext{
46. Eth. 380 .

47. Ibd.
} 
na y externa, querer, sentir, amar, odiar, etc..., externos e internos. El ser de la persona fundamenta todos los actos esenciales diversos» ${ }^{48}$.

Esta descripción fenomenológica general de la persona necesita, sin duda, una exposición detallada, si queremos evitar ciertos quívocos y parcialidades en su interpretación.

Ante todo, se circunscribe, por ahora, nuestra intención a la esfera de la persona en sí misma. En los próximos capítulos trataremos de la persona como independiente en su ser-así de la corporeidad, de lo psíquico y también de la conciencia en general.

Al considerar la doctrina scheleriana de la persona en sí misma, se ha de evitar, en principio, toda postura extrema.

Es casi unánime la actitud de los intérpretes más representativos de $M$. Scheler de encuadrarle dentro de un «actualismo» manifiesto: Entre estos citamos especialmente a E. Przywara ${ }^{49}$, J. Geyser ${ }^{50}, \mathrm{~N}$. Hartmann ${ }^{51}, \mathrm{H}$. Fries ${ }^{52}$, H. E. Hengstenberg ${ }^{53}$, P. Wust ${ }^{54}$, W. Weymann-Weyhe ${ }^{55}$, R. J. Haskamp ${ }^{56}$ y F. Hammer ${ }^{57}$.

Entre los más objetivos encontramos a G. Kraenzlin ${ }^{58}$ y a W. Hartmann quien afirma: «Puede discutirse, ciertamente, si Scheler tuvo una feliz selección de términos, pero es indiscutible que los falsos entendidos de su doctrina sobre la persona proceden las más veces... de no haber considerado todos sus textos" ${ }^{59}$.

En una consideración panorámica de sus escritos en lo referente a la problemática de la persona aparece ésta como concepto-límite entre posturas extremas.

Prescindiendo de las «modificaciones» metafísico-religiosas de su pensamiento, existe en $\mathrm{M}$. Scheler un grupo de expresiones que enfrentan clara-

\footnotetext{
48. Eth. 382-383.

49. Religionsbegründung. M. Scheler-J. H. Newman, 27-31.

50. M. Schelers Phänomenologie der Religion, 60-62.

51. M. Schelers Lehre vom Menschen, 102.

52. Das Problem des geistigen Seins, 56-57.

53. Die katholische Religionsphilosophie der Gegenwart, 56.

54. Philosophische Anthoropologie, 194.

55. Das Problem der Personeinheit in der ersten Per:jde der Philosophie M. Schelers, 63-64.

56. Spekulativer und phänomenologischer Personalismus, 179.

57. Theonome Anthoropologie? M. Schelers Menschenbild und seine Grenzen, 76.

58. M. Schelers phänomenologische Systematik, 34 ss.

59. Daś Wasen der Person. Zur Personlehre M. Schelers, 167.
} 
mente su concepción de la persona a toda interpretación «substancialista» de la misma.

En este sector aparece la persona como «unidad concreta (de actos) sui generis» ${ }^{60}$, "estructura monárquicamente organizada de actos espirituales» ${ }^{61}$, "complejo de actos organizados monárquicamente, e.d., de los que uno lleva en cada caso el gobierno y la dirección» ${ }^{62}$, "unidad (de actos) puramente espiritual» ${ }^{63}$, "ordenación arquitectónica, intemporal e inespacial, de actos» ${ }^{64}$.

Todas estas descripciones apuntan al «hecho fenomenológico» de que la persona «no es... ni ser substancial ni ser objetivo, sino tan sólo un plexo y orden de actos, determinado esencialmente, y que se realiza continuamente a sí mismo y en sí mismo» ${ }^{65}$.

El «sentido» de estas expresiones se halla en la equiparación frecuente realizada por $M$. Scheler entre «substancia» y «cosa», "substancia» y «objeto» ${ }^{66}$.

Al concebir la persona como «unidad arquitectónica de actos» que «varía» en y por cada acto ${ }^{67}$, no. puede entenderse aquélla como ser estático existente «detrás» o "debajo» de los actos. Estas son imágenes insuficientes tomadas de la esfera espacio-temporal, que «no cuenta evidentemente para la relación persona-acto»" ${ }^{68}$.

Podría decirse que $M$. Scheler, en esta perspectiva, se siente obligado a rechazar el concepto de substancia entendida objetivamente, en la que domina la causalidad estricta.

Por eso, precisamente, impugna en la esfera de la persona toda causalidad histórica, biológica y psicológica ${ }^{69}$ puesto que llevarían a la concepción de substancia objetiva ${ }^{70}$.

II

M. Scheler, sin embargo, es consciente de la dificultad que entraña la concepción de la persona sin aceptar el concepto de «substancia». Por esta

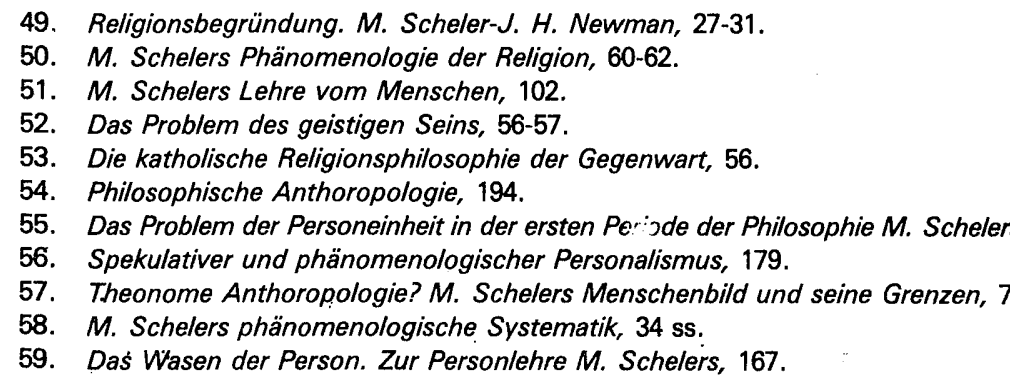


razón no cae en el extremo del «actualismo», como Wundt, a quien rechaza decididamente ${ }^{71}$.

La persona no puede interpretarse en el sentido de "ex operari - esse», ya que uno puede reducirse a la incógnita de un simple punto de partida de actos, ni a cualquier especie de conexión o tejido de actos» ${ }^{72}$.

Aquí precisamente nos parece residir el "sentido" de otro sector de expresiones que a simple vista están en contradicción abierta con las reseñadas anteriormente, y que sin embargo las sirven de complemento, apareciendo la persona, en la descripción fenomenológica scheleriana, en un pendular incesante, complejo y paradójico entre ambos extremos, sin detenerse en ninguno de ellos.

A fin de no caer, pues, en una interpretación parcial, hagamos un pequeño recuento de esta otra vertiente complementaria de la doctrina scheleriana de la persona:

A.- En 1917 aparece el Ensayo En defensa del arrepentimiento, incluido luego en la obra De lo Eterno en el hombre con el título "Arrepentimiento y Regeneración».

En él está investida la persona de un poder sobre sus actos pasados, en virtud del arrepentimiento. Este es capaz de suprimir las culpas pasadas al dirigir la acción "desde el centro vital de la persona» incoando nuevos actos ${ }^{73}$. Cierto que no se puede suprimir la realidad de la acción pasada, pero sí su sentido y valor como acción nuestra.

Con respecto a este texto llega a afirmar $P$. Wust que $M$. Scheler «parece aproximarse aquí a la doctrina cristiana de la unidad de la naturaleza corporeopsíquica del hombre» ${ }^{74}$.

B.- En el Ensayo Para la renovación religiosa, escrito en 1918 e insertado en De lo Eterno en el hombre igualmente, con el título de «Problemas de la Religión», al analizar fenomenológicamente el acto religioso afirma $\mathrm{M}$. Scheler: «La semejanza con Dios... está pues inscrita... en el espíritu humano... en su mismo ser» ${ }^{75}$.

Por otra parte frente a los intentos panteístas que «convirtiendo la relación de semejanza en identidad... destruyen incluso aquélla» ${ }^{76}$, defiende la semejanza del espíritu humano con el divino «en lo referente a la autonomía del ser, a la libertad y a la espontaneidad de la acción».

De manera ulterior entiende $M$. Scheler la antropogénesis auténtica en función de la irrupción de Dios en el hombre, logrando así éste su ser «autónomo» e «independiente».

\footnotetext{
71. Eth. 384 , nota 1.

72. Eth. 383.

73. Ew. M. 36.

74. P. Wust, M. Schelers Lehre vom Menschen, 121.

75. Ew. M. 191.

76. Ibd.
} 
C.- En su breve Ensayo ¿Socialismo profético o marxista? aparecido en 1919 , caracteriza M. Scheler a la persona, contra todos los intentos de concebirla como mera determinación de un principio universal, como «un ser espiritual, individual, substancial» 77 .

D.- En la Filosofía alemana contemporánea, publicada en 1922, se cuenta M. Scheler entre los defensores de una concepción antipanteísta del alma "como substancia autónoma y activa» ${ }^{78}$.

E.- En la obra Esencia y formas de la simpatía (1923), describe M. Scheler la persona como «el único caso de "existencia independiente» (substancia) que está individualizada en sí misma» ${ }^{79}$, «substancia personal» ${ }^{80}$, «substancia unitaria de actos» ${ }^{81}$, «substancia de actos» ${ }^{82}$.

Todas estas expresiones aparecen con las indicadas en el primer punto, siendo también frecuente la expresión "centro de actos»" ${ }^{83}$.

F.- En los Escritos Póstumos, M. Scheler llega incluso, a aceptar «frente a la teoría actualista del espíritu la afirmación «ex esse (de los centros) sequitur operari» ${ }^{84}$.

Frente a esta panorámica de textos, creemos improbable en extremo que M. Scheler acepte y rechace simultáneamente la interpretación «actualista» o "substancialista» de la persona. Su descripción fenomenológica ha de situarse más allá de ambos extremos.

Contra las teorías «actualistas» propugna algo permanente en la persona, pero rechaza inmediatamente el carácter substantivo de este algo.

La persona, pues, aparece en M. Scheler tan compleja y paradógica como su expresión preferida "substancia de actos»" ${ }^{85}$.

Concretamente: si preguntamos por lo que permanece, por aquello que nos posibilita hablar de nuestros actos pasados como «nuestros», nos responde M. Scheler: «la identidad reside exclusivamente en la dirección cualitativa del puro tornarse otro" ${ }^{86}$.

Toda separación entre persona $y$ acto en el sentido relacional de substancia-accidente es rechazada de plano. Frente a la inmutabilidad subs-

\footnotetext{
77. Soz. Welt. 262.

78. Phil. Geg. 206.

79. Sym. 71

80. I.c., 136 .

81. I.c., 180.

82. I.c., 241.

83. I.c., 33; 34, 70, 71, 83, 232, 246.

84. Nachl. 237.

85. Sym. 241.

86. Eth. 385.
} 
tancial está la variabilidad de la persona. Sin embargo, ha de tener, sin duda, algún sentido hablar de la persona como "realizadora de actos»" ${ }^{87}$.

Por otra parte, al brotar del «centro personal» los actos, parece apuntarse al «esse» de la persona como «Centro»: «...este centro está totalmente en cada uno de sus actos, realizando su ser en cada acto" ${ }^{88}$.

Con el término "ser» del centro parece impugnada, ciertamente, toda teoría actualista, sin embargo, de forma inmediata, se rechaza la actitud substancialista con el concepto de ser «co-realizado».

No se trata ni de vacilación ni de contra-sentido. M. Scheler se encuentra, más bien, con la dificultad de expresar en palabras -insertadas en el sistema de coordenadas espacio-temporal de la cosmovisión natural - la vivencia de la persona más allá de todo «substancialismo» y «actualismo». De ahí su oscilar entre ambos, de ahí su negación inmediata de toda postura que parezca enquistarse en alguno de los extremos.

\section{IV}

La persona en M. Scheler es «la concreta y esencial unidad entitativa de actos" ${ }^{89}$ en la que éstos adquieren su esencia concreta al insertarse en ella, no siendo comprensibles ningún acto sin una intuición cognoscitiva simultánea de la esencia «persona» que le realiza.

Toda la persona está en cada uno de los actos particulares y «varía» en y por cada acto.

Ahora bien, "en el concepto de "variación» como puro "tornarse otro» no hay nada de un tiempo que haga posible tornarse otro, ni mucho menos una variación cósica. Tampoco es dado en ella un «sucesivamente» en ese hacerse otro" ${ }^{90}$.

El pensamiento no fenomenológico de la cosmovisión natural permanece aferrado a imágenes espacio-temporales. No le es tan fácil la intuición de la persona supratemporal y supraespacial, ya que se basa en los medios insuficientes del lenguaje orientado igualmente a lo objetivo.

La actitud fenomenológica scheleriana se sitúa, claramente, más allá de toda cosmovisión natural: «Si intentamos presentar en su ser dado ese fenómeno, que es el más oculto de todos, podemos, desde luego, obligar al lector mediante imágenes, a ver en la dirección del mismo fenómeno. En ese caso podemos decir: la persona vive dentro del tiempo; más no vive en el interior del tiempo fenoménico que es dado inmediatamente en el flujo de los procesos anímicos, interiormente percibidos»" ${ }^{91}$.
87. Nachl. 282.
88. Nachl. 238.
89. Eth. 382.
90. Eth. 384.
91. Eth. 385. 


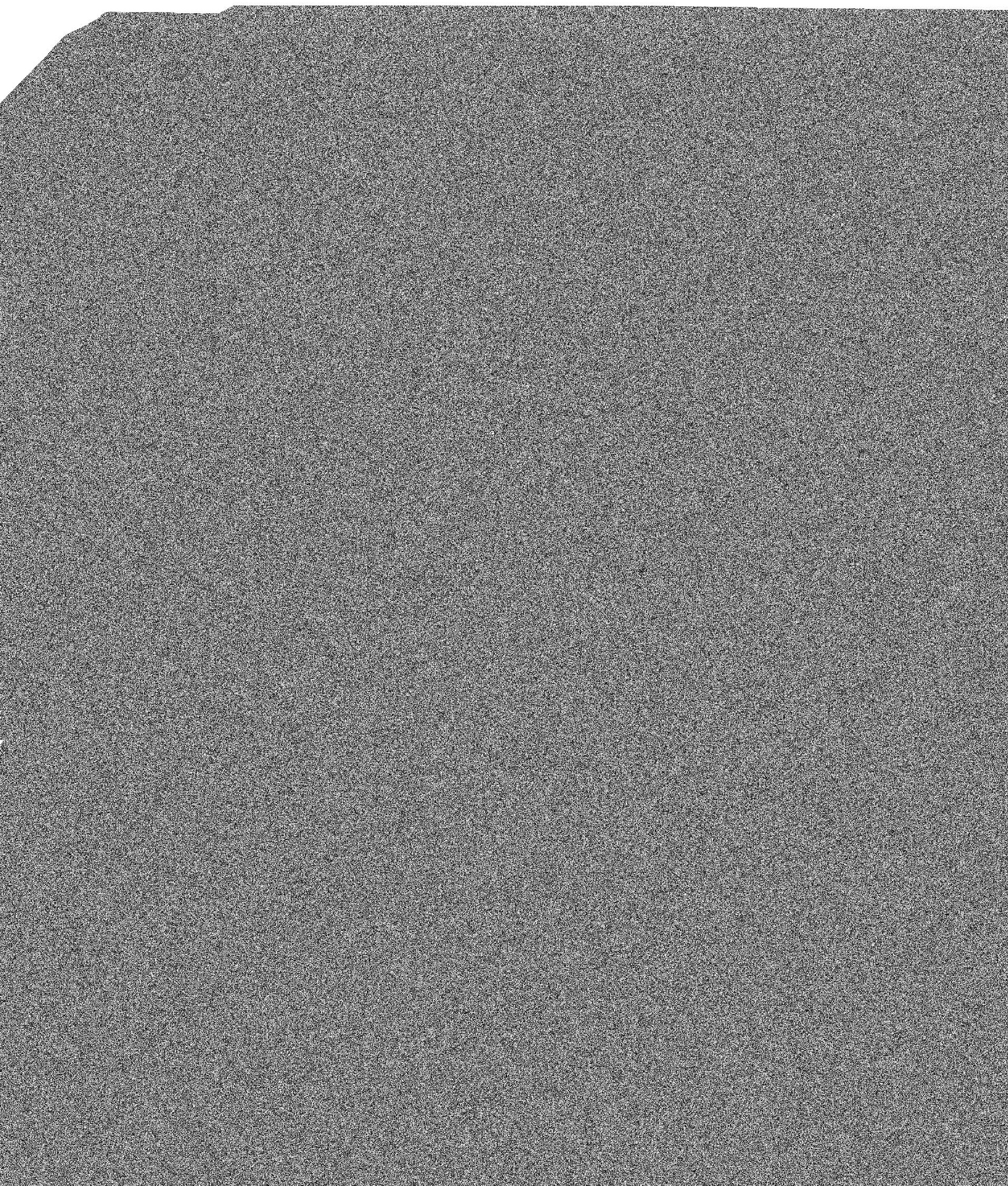


tinto del animal, le lleva a proyectar una metafísica sacra del espíritu en la que la trascendencia de Dios es suprimida, prácticamente, en favor de la trascendencia de la persona humana, que se inserta, de golpe, en el mismo núcleo de la esencia de Dios.

Por otra parte, al negar M. Scheler a la esfera de la persona, por su carácter trascendente, toda causalidad «la vida espiritual-personal logra, sin duda, una supremacía absoluta, pero pierde toda virtualidad histórica»" ${ }^{99}$, hecho que concuerda absolutamente con la impotencia del espíritu, que, como hemos visto ya en la Segunda Parte, aparece clara en De lo Eterno en el hombre ${ }^{100}$. La metafísica dualista del último Scheler, se presenta desde esta perspectiva como simple consecuencia y es el hombre, concretamente, el que nos da la clave.

B.- M. Scheler afirma que la persona «vive» en la realización de sus actos.

Radicalizando la pregunta ¿se ha de interpretar esta «realización» de actos como auto-eficiencia?, creemos que sólo existen dos posibilidades de explicación:

1) La persona, y con ella el acto, es «creada».

Pero por este camino parece introducirse el concepto substancialista de persona. La creación parece presuponer la categoría de substancia.

Según esto, es acertada la afirmación de Hengstenberg: "Hemos de rechazar la concepción de que la persona del hombre - está hablando de $\mathrm{M}$. Scheler - se origina en un punto temporal por creación... El hombre es persona desde el mismo inicio de su existencia o nunca»" ${ }^{101 .}$

2) La persona consiste en la co-realización de los actos de Dios. Ella es lo Eterno en el hombre, la epifanía de Dios en el hombre, élla tiende a ser lo que es, parte de la esencia de Dios. De esta forma el panteísmo esencial parece inherente a la concepción scheleriana de la persona. Sobre este punto volveremos expresamente en la Segunda Sección de esta Tercera Parte.

\section{CRÍTICA DE N. HARTMANN}

En varios pasajes de su Ética ${ }^{102}$ y de El problema del ser espiritual ${ }^{103} \mathrm{~N}$. Hartmann entra en abierta polémica con el concepto scheleriano de persona.

A su vez, M. Scheler en el Prólogo a la Tercera Edición (1926) de El Formalismo en la ética y la ética material de los valores muestra, por una parte, «su gran satisfacción... porque un investigador de la talla, independencia y vi-

99. F. Kaufmann, Geschichtsphilosophie der Gegenwart, 108.

100. Ew. M. 234.

101. Philosophische Anthropologie, 352.

102. Ethik, 3. Aufl., Berlin: De Gruyter 1949: Sujeto y persona, 185-186; Doctrina scheleriana sobre la persona y el acto, 228-232; Posibilidad ontológica de la libertad personal, 765-766.

103. Das Problem des geistigen Seins, 2. Aufl. Berlin: De Gruyter 1949: La vida espiritual como realización de actos, 56-58; Tejido de actos y unidad de persona, 139-140. 
gor científico de N. Hartmann»" ${ }^{104}$ haya "continuado» parcialmente su obra, aunque sea consciente, al mismo tiempo, de la critica de la que es objeto y la rechace expresamente por «injustificada» ${ }^{105}$.

M. Scheler se defiende atacando: «Hartmann ha ido a parar a un realismo ontológico... tan claro que recuerda casi al medievalismo" ${ }^{106}$.

Ahondemos ahora en las razones primordiales por las que M. Scheler encuentra «injustificada» la "crítica» de N. Hartmann, prescindiendo concretamente de la óptica general desde la que ambos abordan su problemática: $\mathrm{N}$. Hartmann desde la atalaya de un "Ateísmo postulatorio» y $\mathrm{M}$. Scheler desde una visión axiológica fundamentada y rematada por el valor de lo «Santo» y la «ldea» de Dios.

A.- Lo que critica N. Hartmann ante todo es uel concepto actualista de persona» en M. Scheler. Admite, inicialmente, la posibilidad de caracterizar los «actos» a través de los conceptos de urealizarse» (sich vollziehen) y urealización» (Vollzug), pero rechaza que puedan aplicarse a la persona:

«Bajo el término de realización ha de entenderse obviamente algo más que un simple suceder neutral, algo más que un proceso. Si la «realización» fuera mero suceso, la compartiría el ser espiritual con los procesos naturales inferiores. Si se tiene que entender algo más, toda realización ha de apuntar a un "realizador» activo. De esta forma, en el trasfondo de toda realización se encuentra un 'realizador'» ${ }^{107}$. La dimensión aporética que N. Hartmann señala en su crítica se cifra en que, según él, para $M$. Scheler la "persona» es la «realizadora» de actos, consistiendo simultáneamente en cuanto "espíritu» «en la realización»: "Entonces ¿se realiza ella misma por un realizador? ¿Se encuentra acaso algún otro detrás de ella? $¿ O$ se realiza a sí misma? ${ }^{108}$.

Tres notas podríamos poner al margen de esta crítica de N. Hartmann:

- Habría que recordarle que M. Scheler no pretende ningún concepto metafísico de la persona, ya que su actitud, al menos intencional, es eminentemente fenomenológica. Podría, pues, objetarse a N. Hartmann que el trinomio «realizador-realizar-realizado» es sólo una imagen antropomórfica que reproduce el orden de sucesión de la acción observada por el hombre dentro de la "cosmovisión natural-ingenua», trascendida claramente por la actitud fenomenológica.

- A N. Hartmann le pasa desapercibido el que M. Scheler se formule expresamente la pregunta sobre «el realizador de actos» ${ }^{109}$.

- Por lo demás, también se encuentran en N. Hartmann expresiones de marcado actualismo, sin que por este motivo esté justificada la interpretación

104. Eth. 19.

105. Eth. 21.

106. Ibd.

107. Das Problem des geistigen Seins, 57.

108. Das Problem des geistigen Seins, 57.

109. Eth. 380. 
actualista de la persona en él; como ejemplo tendriamos las siguientes: "La persona consiste en la unidad de realización de actos» "10: "La vida de la persona consiste en el tejido de actos emocionales trascendentes»" ${ }^{111 .}$

B.- Un segundo punto de discrepancia y crítica lo encuentra N. Hartmann en el carácter inobjetivable de la persona:

«Puede darse, ciertamente, una percepción interna del yo y de sus funciones, pero no de la persona y sus actos. Se presupone siempre que la percepción interna, en sentido psicológico, es la única formalidad del saber sobre lo que aquí se pregunta. Este presupuesto es precisamente controvertible. Pero si no existe ninguna posibilidad de considerä los actos y las personas como objetos la ética sería entonces un imposible» ${ }^{112}$.

Digamos ante todo que N. Hartmann se basa en un concepto de objeto mucho más amplio, más primitivo. Mientras que $\mathrm{M}$. Scheler distingue meticulosamente entre actos de percepción (interna-externa) y actos de aprehensión de los valores ${ }^{113} \mathrm{~N}$. Hartmann unifica ambas regiones de actos, interpretándolas como "maneras de tener objetos» y rechaza que la percepción interna, en sentido psicológico, sea la única forma posible de «saber-algo» en la esfera cognoscitiva de los actos y de la persona.

Aquí tenemos la grave sospecha de que esta afirmación que N. Hartmann atribuye a $M$. Scheler no se encuentre en absoluto en éste. Lo que niega realmente $M$. Scheler es que la persona pueda ser objetivada «en el amor» o "en otros actos genuinos, aunque sean actos de conocimiento» ${ }^{114}$, aunque se pueda vivenciar «co-ejecutando» sus actos:

- cognoscitivamente, en el "comprender» y el "vivir lo mismo» y

- moralmente, «siguiendo su ejemplo» ${ }^{115}$.

Lo mismo es válido también para los valores inherentes a la persona: Pueden aprehenderse como objetos los valores de lo corpóreo y de lo anímico, incluso los valores no-morales de la persona, como su capacidad intelectual o artística, pero nunca podrá ser «objeto» la persona y su valor moral específico.

Por cierto que, más allá de la reflexión psicológica, N. Hartmann distingue «una forma primaria de percepción de la persona, la más viva, concreta e individualizada» que entiende como «algo inmediato y sumamente misterioso en su inmediatez» "116: en ella se incluye "un sentir directamente la realización del acto de la persona ajena» ${ }^{117}$.

110. Ethik, 233.

111. Das Problem des geistigen Sęins, 139.

112. Ethik, 229.

113. Wi. Gees. 104, 341.

114. Sym. 180.

115. Ibd.

116. Ethik, 231.

117. Ethik, 232. 
Pero lo que no se comprende es cómo N. Hartmann subsuma en lo «objetivado» esta vivencia inmediata de la persona ajena, descrita en vocabulario eminentemente scheleriano.

Desde una perspectiva fenomenológica la crítica de N. Hartmann representa, en este aspecto, una caída vertical en la concepción primitiva y nodiferenciada de "objeto», que amenaza con destruir las intuiciones más esenciales de la ética de los valores, concretamente, la superación del dualismo «razón-sensibilidad» por medio de unas formas aprióricas de experiencia más amplia, p.e., «el sentir axiológico» (das Fühlen-von), el «amor», etc.

No le falta, pues, razón a M. Scheler cuando, sin más explicaciones, califica de «injustificada» la crítica de N. Hartmann a su «Personslehre» ${ }^{118}$.

118. Eth. 21. 


\section{CAPITULO TERCERO}

\section{RELACIÓN PERSONA-MUNDO}

\section{MUNDO Y VERDAD DE LA PERSONA}

La persona, en cuanto ser espiritual, no está cortada según el patrón del "mundo-circundante» sino "abierta al mundo», tiene "mundo» ${ }^{119}$. El mundo es el correlato objetivo de la persona. Del mismo modo que los actos se estructuran en la unidad de la persona, los objetos intencionales, en su datitud última, están vinculados en la unidad «mundo». Y si a todo acto (intencional) le corresponde un objeto (intencional), «a toda persona (como esencia) le corresponde un mundo (como esencia)»" ${ }^{120}$.

Ahora bien, la comprensión adecuada de la co-relación esencial «persona-mundo» presupone una aclaración del sentido del «mundo» en $\mathrm{M}$. Scheler.

«Mundo» aparece en tres sentidos marcadamente distintos:

a) Puede designar, en principio, la totalidad de los objetos en general. A este "mundo" pertenecen, incluso, los objetos del mundo-circundante (Umwelt) de una esencia corpóreo-espiritual. El «mundo-circundante» es el mundo-resistencia, relativo de existencia con respecto a un ser corpóreopsíquico. Sus objetos están caracterizados siempre por el coeficiente de realidad. El que este ser-resistencia tenga el carácter de objetualidad depende de la espiritualidad de una esencia corporal. Sólo en cuanto participa la esencia corporal del ser espiritual puede elevar a la dignidad de "objeto» los centros de "resistencia» de su mundo-circundante.

b) En contraposición a éste y en un sentido más estricto, designa "mundo» la totalidad de las esencias objetivas y sus conexiones esenciales. En esta significación es el mundo un absoluto que ha de distinguirse de las regiones de objetos relativos de existencia, de los mundos-circundantes y de las formas esenciales que los constituyen. Este sentido de «mundo» implica, propiamente, el conjunto estructural de todos los mundos existentes posibles; es como el marco de posibilidad del ser-mundo; abarca las esencias objetivas

119. Stell. 38.

120. Eth. 381. 
abstractas y sus conexiones esenciales, válidas a priori para todos los posibles mundos reales y objetivos.

c) Ahora bien, del mismo modo que las esencias abstractas de actos exigen un complemento en la esencia concreta "persona», «si es que han de existiri ${ }^{121}$, así las esencias objetivas abstractas necesitan aquella esencia que constituye su condición de existencia, la razón de posibilidad de que alcancen existencia objetiva.

Esta esencia concreta de objeto es, precisamente, el «mundo», en el tercer sentido scheleriano, en cuanto "correlato objetivo de la persona» ${ }^{122}$.

Las esencias objetivas abstractas connotan, pues, con una esencia objetiva concreta, aunque esta connotación sea tan sólo «un aspecto esencial general de todos los mundos posibles» ${ }^{123}$, precisamente porque se da únicamente en la región de las esencias de lo objetivo.

De forma similar a la persona, la esencia «mundo» constituye también una unidad fundamental; es condición del «ser» de las esencias abstractas objetivas $y$, ulteriormente, la forma esencial en la que están vinculadas entre sí aquéllas en una unidad originaria.

Por otra parte, igual que cada persona, como esencia de acto, posee una materia esencial específica, el mundo - correlato objetivo de la persona - ha de ser un concreto-esencial, objetivo e individual ${ }^{124}$.

Las esencias objetivas abstractas sólo poseen su unidad en una esencia objetiva concreta: el «mundo».

Ahora bien, cada objeto dado en los actos de una persona es objeto únicamente en cuanto forma parte del mundo individual de la persona. En la esencia de lo objetivo se encuentra, pues, su pertenencia al mundo personal concreto. Esto no indica, en modo alguno, el estar condicionado el «mundo» por el sujeto individual de actos, sino que manifiesta, más bien, la correlación fenomenológica esencial "persona-mundo».

El mundo, correlato objetivo de la persona, no es, pues, una «idea» en sentido kantiano, sino una esencia objetiva, concreta e individual.

Aquí radica, precisamente, el hecho de que la verdad es absoluta, pero personal $y$, consecuentemente, no universalmente válida. Esta «verdad personal» no implica ninguna clase de relativismos, ya que «se fundamenta en la esencia del ser - no de la «verdad»- el que esto sea así y no de otra manera» ${ }^{125}$.

Lo que es dado a la persona en los objetos está determinado por un contenido esencial absoluto, constitutivo de su mundo y sólo subsistente para sí. Los hechos objetivos relacionados con tal contenido esencial sólo son acce-

\footnotetext{
121. Eth. 283.

122. Eth. 392.

123. Eth. 393.

124. Eth. 392

+25. Eth. 394.
} 
sibles a una persona: Los juicios sobre estos hechos igual que los conceptos en que son aprehendidos sólo son válidos y verdaderos para la persona concreta.

Existe, pues, una verdad que no es válida para una pluralidad de personas, sino sólo para la persona individual.

Esta verdad para M. Scheler es absoluta, metafísica, "verdad en sí», al tener como contenido el ser esencial y absoluto del mundo objetivo e individual, "distinto para cada persona» ${ }^{126}$.

"Siendo mundo y persona ser absoluto y estando ambos en mutua relación de esencias, la verdad absoluta únicamente puede ser personal y sólo en cuanto que es impersonal o "válida universalmente», no válida personalmente, debe ser falsedad exclusivamente o verdad acerca de los objetos relativos en su existencia»" ${ }^{27}$.

La validez universal, pues, no tiene nada que ver con la «verdad", sólo puede proporcionar un "criterio» ${ }^{128}$ en la región de objetos relativos en su existencia.

Un «mundo» común a todos sólo puede ser el «mundo circundante».

\section{LA IDEA DEL MICROCOSMOS Y DEL MACROCOSMOS}

Aunque no exista un "mundo" accesible a una pluralidad de personas, $\mathrm{ni}$ una verdad absoluta "universalmente válida», podemos preguntarnos si la pluralidad de microcosmos personales se aúna en un «mundo único, idéntico y real», en un "macrocosmos». Entonces los microcosmos, los mundos personales, sin perjuicio de su totalidad como mundos serían partes de macrocosmos: "La contrafigura personal del macrocosmos sería la idea de una persona espiritual infinita y perfecta. Esa persona debería ser concreta, para cumplir la condición esencial de una realidad. De ese modo la idea de Dios está dada juntamente con la unidad, identidad y unicidad del mundo, en virtud de una conexión de esencias»" ${ }^{129}$.

Igual que cada microcosmos tiene como correlato esencial la persona concreta, el macrocosmos exige, por así decir, una persona infinita concreta ${ }^{130}$.

Con esta inferencia llega $\mathrm{M}$. Scheler a la «ldea» de Dios, al que como persona infinita la corresponde un mundo como totalidad macrocósmica.

Ahora bien, por cuanto la unidad de microcosmos personales sólo es posible en virtud de la idea de Dios, toda comunidad de personas ha de funda-

126. Cfr.: Nachl. 302.

127. Eth. 394.

128. Soz. Welt. 19.

129. Eth. 395.

130. Ya hemos indicado anteriomente que, en $\mathrm{M}$. Scheler, por el solo hecho de que algo sea concreto no es considerado como «real»: Rth. 383, nota 2. 
mentarse en la comunidad con Dios: "Todo amare, contemplare, velle, está enlazado intencionalmente, pues, a un mundo concreto, en el sentido único de un amare, contemplare, cogitare $y$ velle «in Deo» ${ }^{131}$.

La idea del microcosmos y del macrocosmos como correlatos esenciales de la persona es vertebral en el pensamiento scheleriano. En ella se puede vislumbrar, nuevamente, la deificación de la persona, al darse sólo una diferencia cuantitativa entre la persona microcósmica y macrocósmica y al no existir en $M$. Scheler ningún principio de analogía o de ejemplaridad que sirva de frontera entre ambas.

Al ser el macrocosmos correlato esencial de la idea de Dios se vuelve difícil explicar la "creación», igual que resultaba imposible este concepto dentro de la auto-eficiencia de la persona.

Ahora bien, de la correlación esencial persona-Dios, microcosmosmacrocosmos, macrocosmos-Dios a la afirmación de la filosofía final de $\mathrm{M}$. Scheler - «la conciencia del mundo, la conciencia de sí mismo y la conciencia de Dios forman una indestructible unidad estructural»-. ${ }^{132}$ hay, sin duda, muy poca distancia y desde luego, una continuidad lógica de pensamiento. Del hombre «microcosmos» emerge el hombre «microtheos», cualitativamente insertado en el mismo núcleo esencial de la divinidad. Pero como en el hombre hay algo más que «estrato personal» se puede preguntar si es que en Dios también se da ese dualismo ontológico; la respuesta positiva sería pura consecuencia y la negativa pura incongruencia. Dejémoslo esto así; por ahora sólo es nuestro propósito apuntar algo que analizaremos detenidamente en la segunda sección de esta Tercera Parte.

131. Eth. 396.

132. Stell. 88. 


\section{CAPITULO CUARTO}

\section{EL PROBLEMA DE LA UNIDAD EN EL HOMBRE}

\section{LOS CENTROS COMO NIVELES ÓNTICOS DIFERENTES}

A pesar de la «unidad vital psico-física» ${ }^{133}$ para M. Scheler el hombre no forma en sí una unidad cerrada, sino que es más bien algo compuesto y dividido. M. Heidegger señala esta ruptura en el hombre como causa de la imposibilidad de un planteamiento auténtico del problema del sentido del «Da-sein»:

«Lo que obstruye y desvía la pregunta fundamental por el ser del Dasein es la orientación constante hacia la antropología cristiano-antigua, de cuyos fundamentos antropológicos insuficientes prescinde tanto el Personalismo como la Filosofía de la Vidan ${ }^{134}$.

En la breve controversia con el pensamiento antropológico scheleriano, M. Heidegger indica certeramente las fuentes de aquél: la concepción platónico-gnóstica.

Más explícito es H. U. v. Balthasar:

«De forma velada pero continua se presenta nuevamente la ruptura platónico-gnóstica en la imagen scheleriana del hombre que divide a éste en dos elementos: natural-terreno y divino-celeste» ${ }^{135}$.

En su «Período Fenomenológico» ya es el hombre para M. Scheler sólo un concepto que abarca diferentes niveles ónticos, absolutamente irreductibles: "Persona», "Yo-Cuerpo». Cuanto más se libera el Centro Personal de actos del Yo, cuanto más independencia manifieste la persona frente a toda causalidad bio-psíquica, tanto más intenso será el estado de libertad interna de la persona ${ }^{136}$.

133. Nachl. 367.

134. M. Heidegger, El ser y el tiempo, México: F.C.E. 1974, 53.

135. H. U. v. Balthasar, "Scheler», en: Apokalype der deutschen Seele, Bd. III, Die Vergöttlichung des Todes, Salzburg-Leipzig: Meiner 1939, 161.

136. Eth. 331-345, Sym. 193-194. 
Gráficamente nos podríamos representar el siguiente esquema:

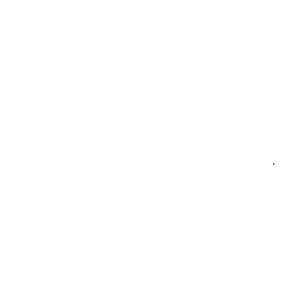

\section{CENTRO}

Cuerpo

Yo-alma vital

Persona

\section{CORRELATO}

Sensaciones orgánicas Funciones psíquicas o egoicas

Actos espiritualespersonales

"La persona está 'elevada' (erhoben) y en su pureza 'se cierne' (erhaben) sobre su cuerpo y sobre su 'vida'... que son sólo condiciones de su existencia terrena» ${ }^{137}$.

El cuerpo es "una cárcel obscura»" ${ }^{138}$.

Esta división del hombre en un principio espiritual y otro corporal, que ha de tener una proyección inmediata en el Dualismo Metafísico de la Filosofía scheleriana final, es de todo punto incontrovertible.

Por otra parte, el origen gnóstico de la imagen del hombre en M. Scheler apenas si se puede discutir:

«Esto es precisamente 'gnosis': que dentro de esta mortalidad se oculta un núcleo esencial divino que viviendo en lo extraño espera ser redimido de su ser mortal... Esta chispa divina se llama Espíritu» ${ }^{139}$.

Entre la persona y el cuerpo se encuentra el Yo.

M. Scheler habla también del "Yo vital», "Centro vital» ${ }^{140}$ que dentro de la estructura total humana constituye:

«El punto medio entre la conciencia del cuerpo, que abraza específicamente en unidad todas las sensaciones orgánicas y los sentimientos sensibles localizados y el ser persona noético-espiritual, como centro de todos los actos intencionales 'supremos' $»{ }^{141}$.

Entre la «persona» y el "centro vital» únicamente se da una «unión dinámico-causal» ${ }^{142}$ :

«El Yo vital y el substrato del mismo, el alma vital, representan como la 'infraestructura' que determina el hecho de que puedan darse los actos noéticos de la persona espiritual en el hombre y a la vez el 'instrumento' de este centro personalı) ${ }^{143}$.

137. Sym 83.

138. Ew. M. 335.

139. F. Leist, Biblische und gnostische Seinserfahrung, Salzburg: O. Müller 1958, 341.

140. Smy. 37, 85, 118.

141. Sym. 33.

142. Sym. 83.

143. Sym. 110. 
La separación entre "Persona» y "Yo» (Espíritu y Psiché) es tan radical que el lugar originario de la esfera de los actos y de la región de lo psíquico pertenecen a reinos ónticamente diferentes; el mundo psíquico no se constituye por una referencia peculiar al "espíritu», sino por la región objetiva que le sirve de base ${ }^{144}$.

A pesar de esta falta de conexión entre Persona y Yo, a pesar de que pertenecen a niveles ónticos diferentes, existe un paralelismo, una sorprendente analogía entre ambos ${ }^{145}$ : El Yo "vive» en sus vivencias como la persona en sus actos; toda vivencia psíquica pertenece a un Yo igual que todo acto a una persona.

Sorprende, sin duda, que M. Scheler subraye esta analogía, ampliándola, como hemos visto, a la intemporalidad del Yo, en abstracción del Cuerpo.

La "persona» y el "Yo» son dos Centros ónticos irreductibles entre los que únicamente puede existir la relación intencional de los actos de la persona, por cuanto el Yo y sus vivencias psíquicas pueden ser objeto de un acto personal de percepción interna: Pero ya sabemos que entre "objeto» y «acto» se da una irreductibilidad absoluta.

Al insertar, por una parte, la "persona» en la esfera del «Espíritu» (Geist), como lo Eterno en el hombre e «idéntica» a la esencia de Dios ${ }^{146}$, $y$ al volatilizar, por otra, lo «psíquico» en lo «vital», aparece el Dualismo Metafísico que llena, en explicación consecuente, la etapa final de la Filosofía scheleriana. El Hombre en $M$. Scheler es quien nos da la clave al ser «microcosmos» $y$ «microtheos».

\section{ESTRATIFICACIÓN (Schichtenbau) DE LA VIDA EMOCIONAL}

Teniendo en cuenta la concepción scheleriana de los centros ónticos como niveles distintos e irreductibles, la «Estratificación de la vida emocional» es una descarada inconsecuencia.

Los «centros ónticos» y los «estratos (Schichten) emocionales» en "EI formalismo en la ética y la ética material de los valores» - (A) - y en «Esencia y formas de la simpatía» - (B) - pueden representarse en el siguiente esquema:

CENTRO

Cuerpo

\section{ESTRATO EMOCIONAL}

(A) Sentimientos sensibles Sentimientos corporales 37 ss.

144. Cfr.: B. Lorscheid, Schelers Phänomenologie des Psychischen, Bonn: Bouvier 1957,

145. Eth. 421.

146. Sym. 141 
CENTRO

Yo-alma vital

Persona
ESTRATO EMOCIONAL

Sentimientos vitales

Sentimientos anímicos puros

Sentimientos espirituales puros
(B) Unificación afectiva Simpatía

Amor

Este esquema es, sin embargo, forzado: Los centros ónticos y los estratos emocionales no se corresponden enteramente entre si e incluso muestran claras incompatibilidades.

Por una parte, M. Scheler inserta en lo "puramente psíquico», constituido por el Yo, estructuras emocionales relativas al cuerpo.

Por otra, y dentro de la teoría de los estratos emocionales, lo "psíquico» y lo "espiritual» no están contrapuestos de forma tan disyuntiva como la esfera de los actos y la de los objetos en la concepción de los "céntros ónticos».

\section{FUNDAMENTACIÓN DE LA PERSONALIDAD}

La imagen scheleriana del hombre, cuadriculada en "centros ónticos» y en "estratos emocionales» inspira todo menos la idea de unidad.

La unidad del ser personal no deriva ni del Yo ${ }^{147}$, ni de la Conciencia ${ }^{148}$, ni tampoco de la Voluntad ${ }^{149}$. De forma similar rechaza M. Scheler todo concepto unitario supra-individual, según el que la persona sería un «modo» o "función» de un Espíritu Universal entendido como «Razón Trascendental» (Fichte), «inconsciente» (E. v. Hartmann) o «Conciencia Trascendental» (Husserl); esto sería «el mayor de todos los errores metafísicos» ${ }^{150}$.

También impugna $M$. Scheler el que la persona esté individualizada por su propio cuerpo: aunque exista una correlación entre la persona concreta y su cuerpo, siendo incluso una intuición esencial la pertenencia de un cuerpo a la persona ${ }^{151}$, y aunque la persona sólo pueda expresarse mediante un Yo, un Centro vital y, por tanto, un cuerpo, sin embargo, su "So-sein» es absolutamente independiente del "So-sein» de su propio cuerpo; las diferencias del «ser-así» de las personas no se basan de ninguna forma en aspectos diferenciales del ser-así de sus cuerpos:

"Las personas, aun cuando prescindamos de sus cuerpos y de la distinción de éstos en el sistema espacio-temporal... se diferencian siempre por su propia esencia como centro concretos de actos. Se distinguirían, pues, aun

147. Eth. 377 .

148. Eth. 391.

149. Eth. 60.

150. Sym. 83.

151. Ew. M. 332; Nachl. 49. 
cuando se pudiera imponer a sus cuerpos $y$ al contenido total de sus conciencias una plena 'coincidencia'. Más aún, son los únicos casos de 'existencia independiente' (substancia) que están individualizadas exclusivamente en si misma»" ${ }^{152}$.

A esta distinción individual de las personas, dadas en su ser-así puro e.d., en su esencia, se refiere $M$. Scheler cuando las designa como uindividuos absolutos».

Con esto tenemos esbozada la doble vertiente - negativa y positiva - de la concepción scheleriana de la persona en lo referente a su fundamentación; en su dimensión positiva implica una problemática dual: identidad e individuación.

\section{IDENTIDAD DEL SER PERSONAL}

La identidad de la persona intemporal e inespacial, en cuanto «substancia de actos» no puede basarse en una continuidad temporal, como pretenden las teorías substancialistas:

"La identidad reside exclusivamente en la dirección cualitativa del puro tornarse otro" ${ }^{153}$.

"La persona íntegra se halla en cada acto plenamente concreto y 'varía' también la persona en y por cada acto, sin que su ser se agote en cualquiera de sus actos o 'cambie' como una cosa en el tiempo") ${ }^{154}$.

La identidad de la persona, por tanto, es posible únicamente en la esfera supra-temporal. Sólo allí tiene un sentido la fórmula paradógica que describe la «perfectibilidad» de la persona: «Llega a ser quién eres».

\section{INDIVIDUACIÓN DE LA PERSONA}

La independencia de la persona con respecto a su propio cuerpo podría decirse que es la "condición negativa» de la posibilidad de la teoría scheleriana de la individuación del ser personal que $M$. Scheler formula de dos formas:

a) «La persona es la forma de existencia única, esencia y necesaria del espíritu, mientras se trate del espíritu concreto" ${ }^{155}$.

b) «Este espíritu está individualizado en sí mismo, no según su «Da-sein» sino según su «So-sein» ${ }^{156}$.

Trataremos primeramente de esta segunda formulación, que es menos compleja que la primera con respecto a sus posibles consecuencias.

152. Sym. 71.

153. Eth. 385

154. Eth. 384 .

155. Eth. 389.

156. Phil. W. 34 . 
La Tesis de la individuación del ser-personal en sí mismo aparece con impenitente reiteración en el pensamiento scheleriano, pero sobre todo en su obra "Esencia y formas de la simpatía» ${ }^{157 .}$

En virtud de esta Tesis, W. Hartmann vincula a M. Scheler con todos aquellos pensadores que desde finales de la Edad Media colocan en la utotalidad óntica» ('tota entitas') el principio de individuación ${ }^{158}$.

Para demostrar su Tesis sobre la individuación del ser personal por sí mismo podríamos recurrir a estas dos razones:

- En la estructura emocional de la simpatía «la distancia de las personas y la conciencia, tanto propia como recíproca, de su diversidad, subsiste de forma absoluta» 159 .

Esto tendría una difícil explicación si no se comprendiera a las personas concretas como «realidades individuales, absolutas y autónomas».

- En el ensayo «Muerte y supervivencia», publicado en sus «Escritos póstumos» (1933) M. Scheler destaca la independencia de la persona en su «Sosein» con respecto al cuerpo: Parte de la experiencia de que al contenido de lo dado en cualquier acto espiritual le caracteriza una "superabundancia» frente a los estados somáticos respectivos, que, en la muerte, polariza en un acto en el que la persona se experimenta como «escapándose» del cuerpo ${ }^{160}$.

Estos dos pasajes de la obra de M. Scheler se complementan con la afirmación según la que:

«las substancias-personas o las substancias-actos son las únicas que poseen una genuina esencia individual y su existencia distinta se sigue, en primer término, de esta su esencia individualizada en sí. En razón de esta esencia tiene también cada substancia espiritual su destino individual...» ${ }^{161}$.

a) Analicemos ahora la primera formulación en virtud de la que un espíritu concreto sólo puede existir esencial y necesariamente como «espíritu personal».

Esta afirmación podría resumir drásticamente toda la problemática en torno a la continuidad o discontinuidad del pensamiento scheleriano.

Ante todo, digamos que no puede limitarse a la esfera del espiritu humano; a pesar de su carácter general, la afirmación es precisa: "Todo espíritu, necesaria y esencialmente, es persona» ${ }^{162}$. "La idea de un 'espíritu impersonal' es absurda».

157. Sym. 35, 71, 72, 73 nota $1,83,136,262$.

158. «Esta concepción defendida por P. Aureolo, G. Biel y F. Murcia entre otros, fue reincorporada por Leibniz en su 'Disputatio metaphysica de principio individui' (1663)», W. Hartmann, «das Wesen der Person. Zur Personlehre M. Schelers», en: Salzburger Jahrbuch für Philosophie, IX-X (1966-1967), 174.

159. Sym. 70.

160. Nachl. 9 ss., 42 ss., 46 ss.

161. Sym. 136.

162. Eth. 389. 


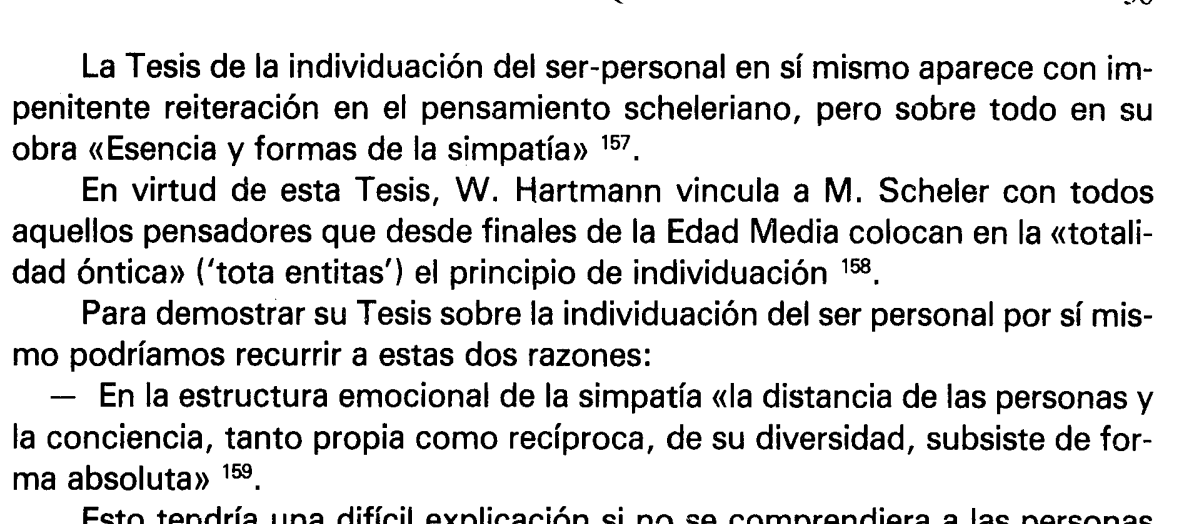

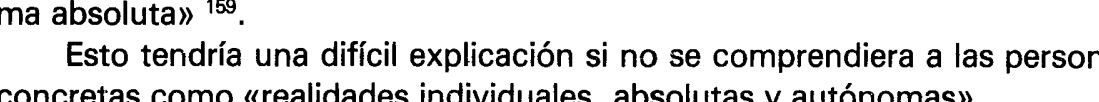
(x)

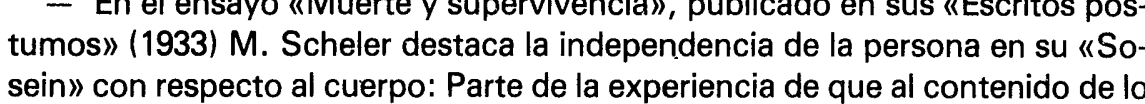
(n) (3) (a)

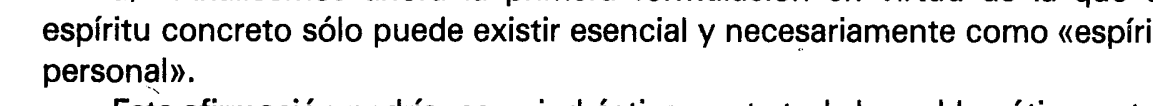

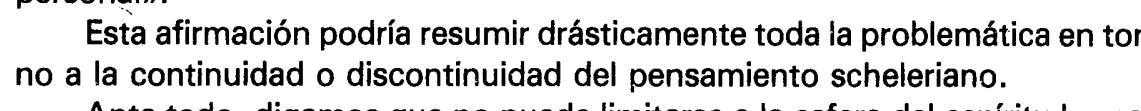

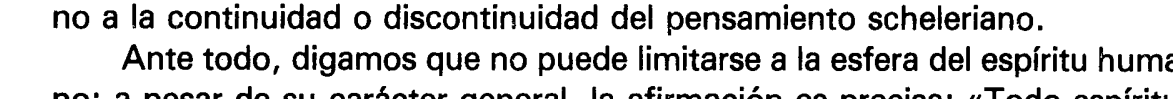

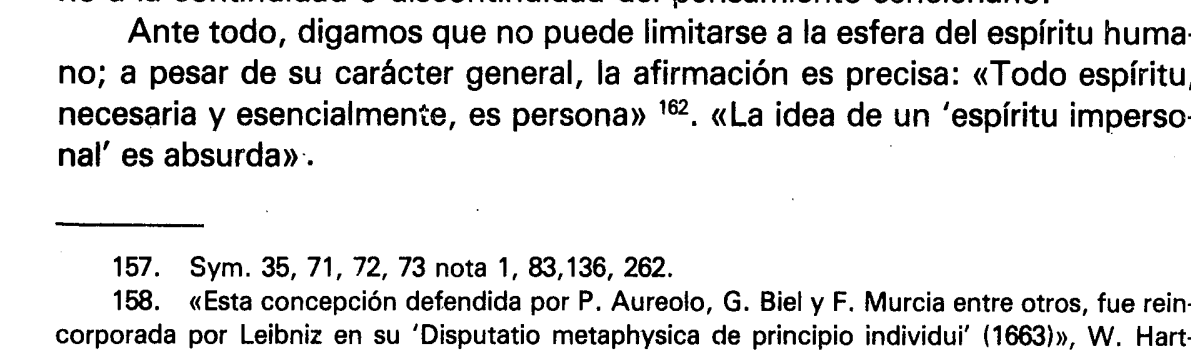

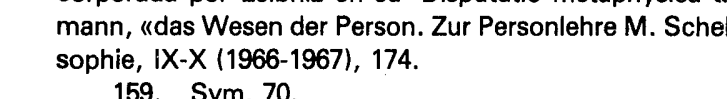


«sistema de conformidad» ${ }^{175}$, como una «nivelación» (Ausgleich) ${ }^{176}$ entre las distintas posibilidades cognoscitivas reseñadas que parece quebrarse siempre que $M$. Scheler se coloca sobre una perspectiva noética concreta, pero que debe surgir, al menos como objetivo intencional unitario, al aglutinarse las diferentes perspectivas parciales.

M. Scheler, pues, habla unas veces de Dios en cuanto «Dios de la religión pura» ${ }^{177} \mathrm{y}$ otras en cuanto "fundamento metafísico del mundo», al que corresponde además de la «espiritualidad», la "vida universal». Incluso se da en M. Scheler una superposición de conceptos como cuando habla de «Dios en Dios»):

«si la primera vez entendemos por Dios el Dios de la pura religión y la segunda, Dios como principio metafísico del mundo" ${ }^{178}$.

Frente a la "fenomenología de la persona», en los Escritos finales (1922. 1928), aparece una "metafísica de los actos», y frente a la "fenomenología de la Esfera del Absoluto" y su proyección sobre el hombre como simple "teomorfismo», M. Scheler describe las grandes líneas de su «Antropología Filosófica: Ya no es central el tema de Dios, la centralidad la ostenta ahora el hombre.

Al cambio de perspectiva noética corresponde un cambio de contenido significativo: Ya no se ve al hombre desde Dios (teomorfismo) sino a Dios desde el hombre (antropomorfismo), al ser éste umicrocosmos» $y$ umicrotheos) ${ }^{179}$.

A través de la deducción trascendental $M$. Scheler se asoma ahora al "Weltgrund" o fundamento metafísico del mundo que, en su marcha procesual como "Dieu qui se fait», concuerda sólo en su final con el Dios teísta al ser éste «meta ideal» del proceso cósmico universal.

Pero de todo esto hablaremos detenidamente al analizar el pensamiento antropológico de la etapa final de M. Scheler.

\section{EL PROBLEMA DE LA LIBERTAD}

Sorprende un tanto el que $M$. Scheler no publicase ningún estudio sistemático del problema de la libertad, radicado como está en el núcleo más íntimo de la persona.

Nos encontramos, es cierto, con alusiones expresas ${ }^{180}$ que nos indican la preocupación de $M$. Scheler por «las preguntas obscuras que hacen surgir el

175. Ew. M. 142.

176. Phil. W. 89.

177. Sym. 142.

178. Ibd.

179. Phil. W. 14.

180. Eth. 211, $245,593$. 
problema de la libertad» ${ }^{181}$, pero la desacostumbrada amplitud de su obra ética le impide insertar un capítulo especial dedicado a tal problema ${ }^{182}$. Sólo en sus Escritos Póstumos (1933) aparece un Ensayo que lleva como título Fenomenología y metafísica de la libertad ${ }^{183}$ y que debió ser escrito el último año de la publicación de su obra ética (1916).

Nuestra exposición girará entonces a este Ensayo. En él no parte M. Scheler de una postura crítica frente a Kant, sino que con una actitud fenomenológica clara se coloca dentro de la conciencia inmediata de la libertad ${ }^{184}$ manifestando como consecuencia su oposición directa a la postura kantiana sobre la libertad.

Dentro de una doctrina como la kantiana, que mide el ser-libre del individuo por la congruencia relacional con la universalidad de un deber-ser ideal, es pura consecuencia el que aparezca la voluntad como debiendo hacer algo.

Ahora bien, una inferencia de esta índole es totalmente innecesaria si la existencia moral autónoma no está fundamentada en la trascendencia de una razón supraindividual ni en el deber ser que emerge de élla, sino en la inmediatez del ser personal que se experimenta como tal en su misma individualidad. «Individualidad» no significa «singularización» de algo genérico en virtud del hic et nunc de su existencia empírica, sino - como hemos visto- la esencia de una persona única y original, en la que lo histórico-accidental y lo esencial-necesario están concretados en un centro irrepetible de actos. Esta concreción corresponde a la igual originalidad de la conciencia de upoder» y «deber» como experiencias moralmente relevantes y no deductibles por tanto.

A la afirmación kantiana «Puedes pues debes» opone M. Scheler el punto de vista de Lutero "A debere ad posse non valet consequentia»" 185.

Al no fundamentarse la vivencia de "poder» en la de "deber-ser»-ya que es igualmente originaria - hay que concluir que todo deber-ser-normativo presupone una vivencia potencial de «poder».

Para M. Scheler, la experiencia inmediata de la libertad en el hombre se realiza primordialmente en la conciencia de "poder», no de «deber-ser», y esto en un doble sentido: Por una parte experimenta el hombre el poder de la voluntad, su capacidad para tomar una determinación, por otra tiene la vivencia de poder-otra-cosa y con ella la libertad de elección ${ }^{186}$.

Mientras la primera experiencia connota la conciencia de una espontaneidad y eficiencia original y autónoma de la persona, la segunda vivencia se basa en la primera: la fuerza para decidirse por otra cosa, para comportarse de

181. Ibd.

182. Eth. 593 nota 211.

183. Nachl. 157-177.

184. Nachl. 157.

185. Eth. 243.

186. Nachl. 157. 

Podríamos decir que la libertad interna del poder obrar en cuanto tal no es ni puramente subjetiva ni objetiva, es más bien una categoría personal fenoménicamente mediadora entre ambas regiones.

En oposición a Kant, para quien la libertad es sencillamente una propiedad de la voluntad ${ }^{195}, M$. Scheler afirma: «Libre» "es originariamente un atributo de la persona $y$ no de ciertos actos (como "querer») no del individuo" ${ }^{196}$. Ser libre significa, pues, ser autoeficiente, y puesto que el símismo como persona sólo existe en la realización de sus actos, ser en concreto eficiente en una conexión significativa de actos.

Esta afirmación debe ser explicada en dos sentidos:

a) Si la libertad está vinculada a la realización de los actos en su conexión significativa personal concreta, la persona obrará tanto más libremente cuanto más intensamente participe la totalidad de la persona, con toda su tabla de valores, en la acción ${ }^{197}$.

b) Libertad significa siempre vinculación y orden. Libertad y orden se comportan de forma complementaria entre sí. No puede excluirse sino que se condicionan recíprocamente: «Libertad es el nombre de una relación vivencial de causalidad superior y amecánica frente a la causalidad inferior y mecánica. Las exigencias objetivas de los valores se dan de manera primordial. Han de ¿er realizadas. Su forma superior de realización es la libertad» ${ }^{198}$.

Hemos de detenernos ahora en la aclaración de estos dos puntos.

a) La conciencia de libertad interna enraizada en la vivencia del poderobrar no puede equipararse a la idea de indeterminación, como tampoco coincide la coacción con la determinación. Estos dos órdenes de contraposición se basan en puntos de vista diferentes.

«Aunque tuviera validez el determinismo teórico... sería posible, sin embargo, la libertad en sentido estricto" ${ }^{199}$.

Nos encontramos con la categoría de la libertad al tomar conciencia de nosotros mismos en la realización de actos e.d., como causas. Desde esta perspectiva es evidente que el grado de libertad en una acción coincide con el nivel de autoeficiencia de la persona, es tanto más intensa cuanto más determine la totalidad del centro de actos a la acción.

La relación entre libertad y determinación se nos presenta, en este sentido, como directamente proporcional, por cuanto "determinación» significa regularidad y posibilidad de calcular un suceso sea de la índole que sea.

Ahora bien, el comportamiento de una persona nos parece tanto más calculable cuanto más libre obra: «Existe precisamente la conexión esencial dè

195. Kant, Grundlegung zur Metaphysik der Sitten, 80 .

196. Nachl. 174.

197. Nachl. 160.

198. Nachl. 164.

199. Nachl. 159. 
que un acto es realizado tanto más libremente... cuanto más determinado esté por la persona») ${ }^{200}$.

Al contrario, el caprichoso e incalculable es aquel que sucumbe ante estímulos situacionales externos. Por otra parte, cuando el hombre forma parte de la masa su obrar es incalculable y... tanto menos libre.

b) En virtud de la fundamentación dual de la libertad sobre la conciencia originaria de "poder» y sobre la eficiencia de la individualidad personal, concreta y esencial $M$. Scheler se enfrenta a Kant en un doble sentido.

En principio descarta un aspecto básico en la ética kantiana: el reconocimiento de la autonomía de todas las categorías del deber-ser ideal frente a las del ser ideal y real.

Por otra parte aunque está de acuerdo con Kant en que libertad en sentido positivo, significa tanto como orden, difieren ambos filósofos en el principio de ese orden.

Mientras que para Kant el deber-ser ideal y su carácter normativo encuentran su fundamento unitario en la ley moral de la razón práctica, la respuesta de M. Scheler es mucho más complicada. Presenta tres principios fontales distintos de los que emergen las proposiciones normativas, entre las que no existe siempre ni necesariamente una relación de complementaridad, sino que son posibles múltiples antinomias.

Según esto, el deber-ser ideal y, consiguientemente, el deber-ser normativo pueden estar fundamentados:

1. En la intuición de «valores universalmente válidos ${ }^{201}$. La validez universal hay que entenderla al menos en relación con un grupo amplio, como un pueblo o una totalidad cultural.

2. En la intuición de la «esencia individual de valor de una persona» 202.

3. En la intuición del ser-conjunto de las personas constitutivo esencial de todo el ser personal ${ }^{203}$.

Tenemos, pues, que el deber-ser ideal se fundamenta siempre en los valores. Esta afirmación básica de todas las éticas (materiales) de valores frente a las éțicas del deber-ser cristaliza en los siguientes axiomas: Todo valor positivo debe ser $y$ todo valor negativo no debe ser.

El carácter fundante del valor se manifiesta primordialmente en su indiferencia con respecto a la existencia o no existencia. Todo deber, por el contrario, es un deber-ser o un no-deber-ser de "algo», concretamente de algo valioso positiva o negativamente.

El ser del valor es un hecho autónomo, fenoménicamente experienciable que existe con independencia de su realización. El valor no está fundamentado en su ser-debido.

200. Nachl. 160.

201. Eth. 483.

202. Eth. 481.

203. Ew. M. 371. 
La independencia de la datitud del valor con respecto a las maneras de darse el ser es la base de la libertad: «Libertad es únicamente la dirección hacia la independencia de la determinación de un acto por las coordenadas de lugar y tiempo del contenido determinante... por eso es la determinabilidad por los valores, futuros y pasados que no influyen momentáneamente en nuestro estado, un signo seguro de libertad» 204 .

\section{(Continuará)}

H. Martín Izquierdo

204. Nachl. 164. 
La independencia de la datitud del valor con respecto a las maneras de darse el ser es la base de la libertad: «Libertad es únicamente la dirección hacia la independencia de la determinación de un acto por las coordenadas de lugar y tiempo del contenido determinante... por eso es la determinabilidad por los valores, futuros y pasados que no influyen momentáneamente en nuestro estado, un signo seguro de libertad» 204 .

\section{(Continuará)}

H. Martín Izquierdo

204. Nachl. 164. 
La independencia de la datitud del valor con respecto a las maneras de darse el ser es la base de la libertad: «Libertad es únicamente la dirección hacia la independencia de la determinación de un acto por las coordenadas de lugar y tiempo del contenido determinante... por eso es la determinabilidad por los valores, futuros y pasados que no influyen momentáneamente en nuestro estado, un signo seguro de libertad» 204 .

\section{(Continuará)}

H. Martín Izquierdo

204. Nachl. 164. 